Research Article

\title{
The Influence of Blade Angle on the Performance of Plastic Centrifugal Pump
}

\author{
Jun Li $(\mathbb{D}$, Lingfeng Tang, and Yaoyao Zhang \\ School of Mechanical and Automotive Engineering, Anhui Polytechnic University, Wuhu, Anhui 241000, China \\ Correspondence should be addressed to Jun Li; 2190110106@stu.ahpu.edu.cn
}

Received 19 April 2020; Revised 25 July 2020; Accepted 28 July 2020; Published 25 August 2020

Academic Editor: Candido Fabrizio Pirri

Copyright $(92020$ Jun Li et al. This is an open access article distributed under the Creative Commons Attribution License, which permits unrestricted use, distribution, and reproduction in any medium, provided the original work is properly cited.

\begin{abstract}
In order to obtain the influence of blade placement angle on the performance of plastic centrifugal pumps, this article used the velocity modulus method. Based on the method, the hydraulic design of the flow passage components of the plastic centrifugal pump was carried out, and the two-dimensional model and three-dimensional model diagram of the flow components were established. The flow field of the impeller model under different working conditions was simulated and the results were analyzed by ANSYS CFX. The influence of different fluid loads on the solid structure under design conditions on the structure characteristics of the impeller was studied by ANSYS Workbench. Impeller models with different outlet angles were established to study the influence of the outlet angle on the performance of pump, and fluid-structure interaction for different impeller models was utilized to study the influence of the outlet angle on the structural characteristics of the impeller. According to the Stepanoff velocity modulus method, considered the import prerotation, the wrap angle design method and the blade inlet angle design method were proposed. In order to study the influence of different inlet angles on the performance of pump, the inlet angle was changed to establish multiple sets of impeller models, $3 D$ printing technology was used to print out each impeller, and performance experiments were performed on the pump equipped with the impeller. The result of the experiments showed that working pressure of plastic centrifugal pump exceeding $5 \mathrm{~atm}$ would cause impeller structure damage. When the outlet angle was $35^{\circ}$, the plastic centrifugal pump reached the highest efficiency of $81.0161 \%$ and the highest $H$ of 35.8029 . The maximum deformation caused by the flow field load on the impeller increased with the increase of the outlet angle. With the increase of the inlet angle, the efficiency and $H$ of the plastic centrifugal pump were reduced. Under normal pressure load, the deformation of the impeller first decreased and then increased, and when $\beta_{1}$ was $13^{\circ}$, the total deformation of the impeller was the smallest.
\end{abstract}

\section{Introduction}

Plastic centrifugal pumps have advantages such as outstanding corrosion resistance, light weight, and low price. They are widely used in various fields of national economic production [1]. In recent years, with the improvement of computer level and the continuous development of numerical simulation methods, Guo [2] studied the law of radial force and rotor mode on the blade of low specific speed by two-way fluid-structure interaction. Liu et al. [3] studied the influence of two-way fluid-structure interaction on the external characteristic parameters of centrifugal pump and analyzed the pressure fluctuation at the outlet of the impeller. Wang et al. [4] carried out numerical analysis and optimization of three kinds of volute structure and obtained the matched deformation between the volute and the blade by the method of one-way fluid-structure interaction. Huang et al. [5] analyzed the whole flow field of IS100-65-200 centrifugal pump considering the flow field loads on the impeller, volute, and the front and back cavities of the impeller. Fontanls and Alfred [6] studied the influence of rotor stator interaction (RSI) on the vibration and acoustic characteristics of the centrifugal pump and studied the interaction between the impeller and diffuser of centrifugal pump with CFD to study its pressure fluctuation. Mou [7] analyzed the stress-strain distribution of the cantilever centrifugal pump impeller under different cantilever ratios by one-way fluid-structure interaction and studied the dynamic characteristics of the centrifugal pump rotor under different cantilever ratios under prestress and nonprestress. 
Tang et al. [8] carried on the thermo-solid coupling analysis to the plastic pump. Wang and Huo [9] have carried out multiobjective optimization design and experiment on the centrifugal pump.

Gu et al. [10] reduced drag by studying the synergistic drag reduction of polymers and surfactants. The above research studies on fluid-structure interaction of the centrifugal pump are all aimed at metal pumps. The strength of the impeller of plastic centrifugal pump is relatively low, so under the fluid load, the elastic deformation of the impeller of plastic centrifugal pump is significantly larger than that of the metal pump. When the fluid load is large enough, the blade will produce obvious deformation and lead to the structural failure of the plastic centrifugal pump impeller. In this paper, a low specific speed plastic centrifugal pump is taken as the research object, and the influence of the blade angle of plastic centrifugal pumps on the pump performance is studied based on one-way fluid-structure interaction.

\section{Structural Design of Plastic Centrifugal Pump}

Basic parameters of the plastic centrifugal pump: $Q=12.5 \mathrm{~m} 3 /$ h, $H=32 \mathrm{~m}, n=2900 \mathrm{r} / \mathrm{min}$, and NPSHa $=4 \mathrm{~m}$, inlet diameter $D_{S}=50 \mathrm{~mm}$, inlet velocity $v_{s}=1.77 \mathrm{~m} / \mathrm{s}$, outlet diameter $D_{d}=40 \mathrm{~mm}$, outlet velocity $V_{D}=2.765 \mathrm{~m} / \mathrm{s}$, and $n_{S}=46.36$. When the flow rate increases, the design parameters of the plastic centrifugal pump become $Q=20.375 \mathrm{~m} 3 / \mathrm{h}$, $H=30.825 \mathrm{~m}$, and $n_{S}=60.871$. Efficiency of the plastic centrifugal pump: $\eta=0.691$; motor power: $P_{C}=2.972 \mathrm{kw}$.

2.1. Determination of Impeller Inlet Diameter. Equivalent diameter of the impeller inlet: $D_{0}=56.24 \mathrm{~mm}$. For a cantilever impeller, impeller inlet diameter $D_{J}=58 \mathrm{~mm}$, blade inlet width $b_{1}=23.43 \mathrm{~mm}$, impeller outlet diameter $D_{2}=158.5 \mathrm{~mm}$. In the hydraulic design of low specific speed plastic centrifugal pump, in order to improve the efficiency of plastic centrifugal pump, the impeller outlet width is $b_{2}=10 \mathrm{~mm}$.

In this paper, the angle of the blade is $20^{\circ}$, the angle of the blade outlet is $\beta_{2}=30^{\circ}$, the number of blades is $Z=5$, and the diameter of the blade outlet is $D_{2}=162 \mathrm{~mm}$.

Outlet shaft speed: $v_{m 2}=1.38 \mathrm{~m} / \mathrm{s}$, outlet peripheral speed: $U_{2}=24.51 \mathrm{~m} / \mathrm{s}$, and blade wrap angle $\varphi=130^{\circ}$.

\subsection{Design of Main Structural Parameters of Pressurized Water Chamber}

2.2.1. The Area of Each Section of Vortex Chamber. Each section of the vortex chamber presents a gradually increasing mode, and the area of each section is obtained by formula (1) and shown in Table 1:

$$
F_{\varphi}=F_{8} \frac{\varphi}{360} .
$$

$F_{\phi}$ : area of each section of vortex chamber, $\mathrm{cm}^{2}$.

$\phi$ : wrap angle of vortex chamber section.

\subsubsection{Vortex Chamber Width}

$$
b_{3}=(1.5 \sim 2.0) b_{2} .
$$

According to the empirical formula of vortex chamber width and $b_{2}=10 \mathrm{~mm}, b_{3}$ is $20 \mathrm{~mm}$. Considering that the material of the impeller is a polymer material, a certain margin needs to be left to compensate the rotor series and manufacturing errors, so $b_{3}$ is $33 \mathrm{~mm}$.

\subsubsection{Base Circle Diameter}

$$
D_{3}=(1.03 \sim 1.08) D_{2} .
$$

From the empirical formula of base circle diameter and $D_{2}=158.5 \mathrm{~mm}$, substitute the value, then $D_{3}=174.96 \mathrm{~mm}$ and $D_{3}=175 \mathrm{~mm}$.

2.3. Model Diagram of Overcurrent Parts. According to the structural parameters of the impeller calculated in the last section, the two-dimensional model diagram of the impeller is drawn.

\subsubsection{Two-Dimensional Design Drawing of Overcurrent} Parts. In [11], a method of drawing cylindrical blade with controllable wrap angle was proposed. In this paper, the blade thickness is uniformly thickened from the inlet to the outlet, the real thickness of the blade inlet is $4 \mathrm{~mm}$, and the real thickness of the outlet is $8 \mathrm{~mm}$. According to the above method of drawing profile, the two-dimensional design drawing of the impeller is shown in Figure 1, and the twodimensional design drawing of volute is shown in Figure 2.

\subsubsection{Three-Dimensional Design Drawing of Overcurrent} Parts. Use SolidWorks 2017 to draw the three-dimensional model of the impeller, as shown in Figures 3(a) and 3(b), and the impeller water model diagram, as shown in Figure 3(c), and establish the three-dimensional model of the volute water body according to the two-dimensional design drawing of the volute, as shown in Figure 3(d).

\section{Flow Field Simulation and Fluid-Structure Interaction Analysis of Impeller}

Based on the results of fluid-structure interaction analysis, the deformation of the impeller under design condition is obtained.

3.1. Simulation of Internal Flow Field of Plastic Centrifugal Pump. The flow field simulation steps of the plastic centrifugal pump are as follows.

3.1.1. Mesh Generation. Due to the complex model of the overcurrent parts of the plastic centrifugal pump and the large change of curvature, after comparative analysis, an unstructured mesh is used for mesh generation, and the steps are shown in Figure 4. 
TABLE 1: The area of each section of the vortex chamber.

\begin{tabular}{|c|c|c|c|c|c|c|c|c|}
\hline Section & 1 & 2 & 3 & 4 & 5 & 6 & 7 & 8 \\
\hline Wrap angle $\varphi_{0}$ & 45 & 90 & 135 & 180 & 225 & 270 & 315 & 360 \\
\hline Area $\mathrm{F} \varphi / \mathrm{cm} 2$ & 0.6 & 1.2 & 1.8 & 2.4 & 3 & 3.6 & 4.2 & 4.8 \\
\hline
\end{tabular}

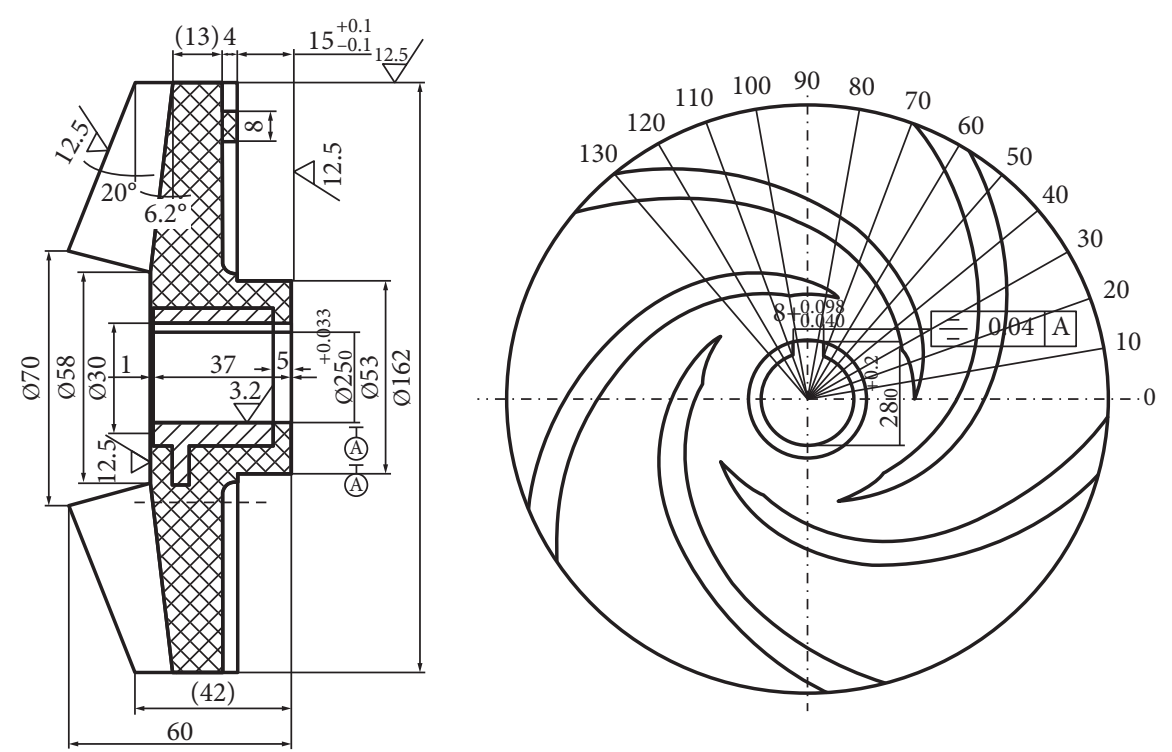

Figure 1: Two-dimensional design of the impeller.
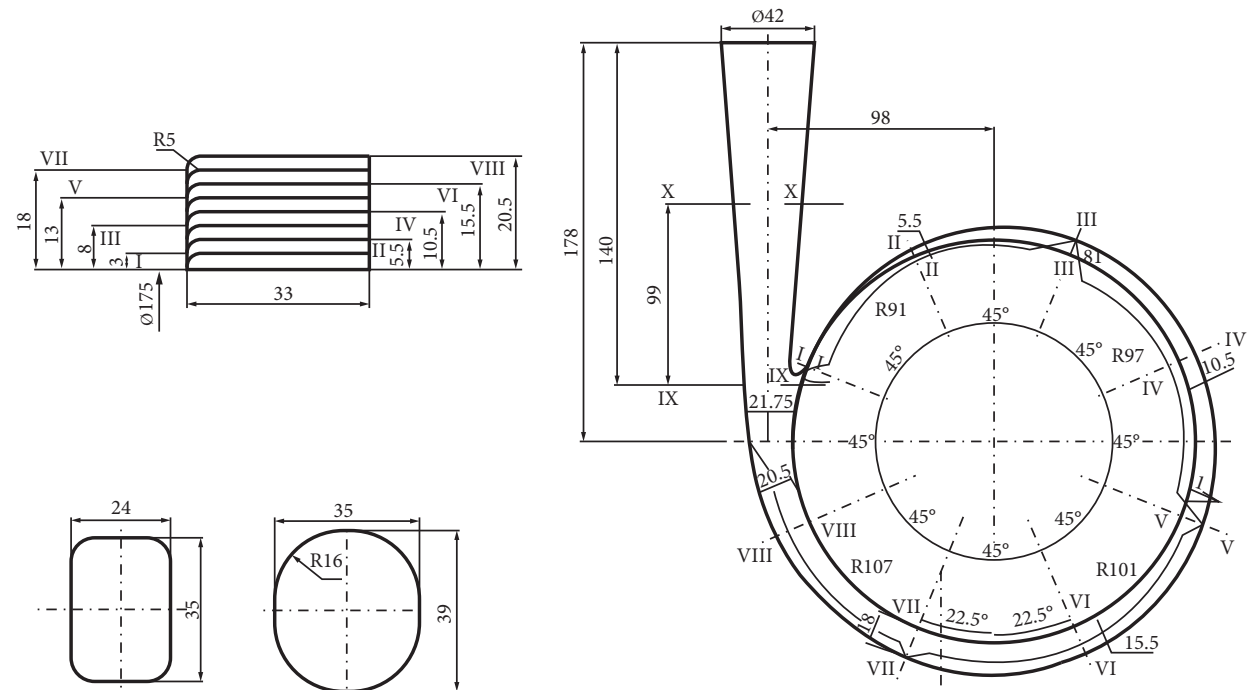

Figure 2: Two-dimensional design drawing of the volute.

The calculation domain of the whole flow field of the plastic centrifugal pump mainly includes the volute part, the rotating area of the impeller, and the extension of the inlet and outlet. The mesh distribution of each calculation domain is shown in Table 2 and mesh division model is shown in Figure 5.

3.1.2. Analysis of Numerical Simulation Results. Figure 6 shows the pressure cloud chart of the impeller model under the conditions of $0.6 Q$ and $1.4 Q(Q$ is the flow at the design working point). It can be seen from the figure that, under the off-design working condition, the pressure distribution on the impeller is uneven, which will cause flow separation, water loss, and vibration of the pump and will reduce the service life of the pump. With the increase of $Q$, the pressure difference between the impeller outlet and inlet becomes smaller, and the pressure at the impeller inlet decreases, so the centrifugal pump is more prone to generate cavitation. It can also be seen clearly from Figure 7 that the effect of flow velocity on the efficiency of centrifugal pump. The flow distribution in the impeller is uneven, which is most obvious 


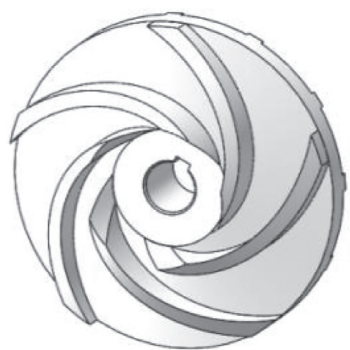

(a)

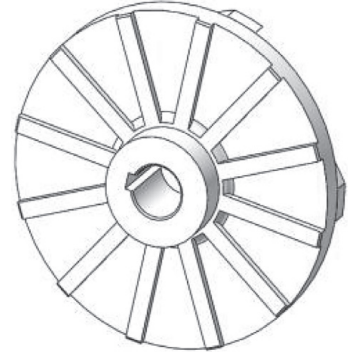

(b)

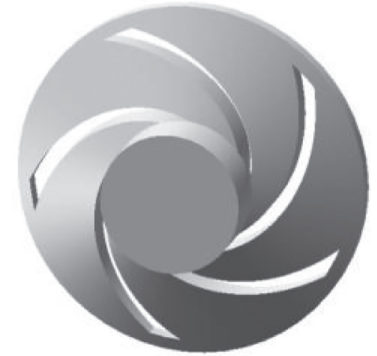

(c)

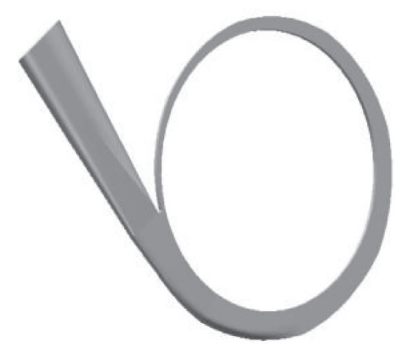

(d)

FIgURE 3: Three-dimensional design of the impeller. (a) Front view of the impeller model. (b) Back view of the impeller model. (c)Impeller water model. (d)Volute water model.

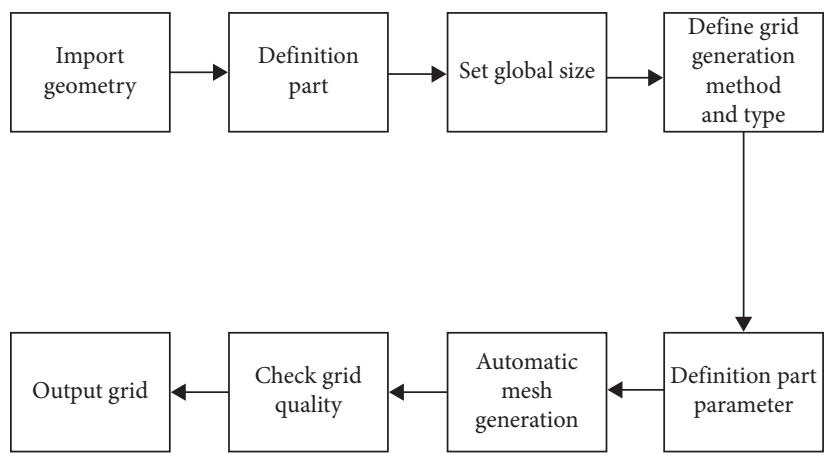

FIgURE 4: Unstructured mesh generation steps.

Table 2: Mesh distribution.

\begin{tabular}{lcccc}
\hline Computational domain & $\begin{array}{c}\text { Inlet } \\
\text { extension }\end{array}$ & Impeller & Volute & $\begin{array}{c}\text { Outlet } \\
\text { extension }\end{array}$ \\
\hline Number & 362444 & 715419 & 653367 & 238182 \\
\hline
\end{tabular}

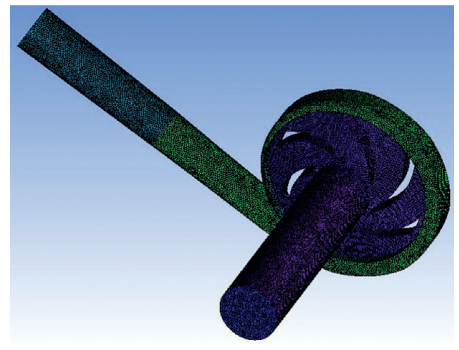

Figure 5: Mesh division model.

under the condition of the small flow rate. This situation is basically consistent with the result of the pressure cloud chart.

In order to study the cavitation performance of the plastic centrifugal pump under the design condition, the inlet pressure of the plastic centrifugal pump is continuously reduced until the cavitation occurs. The gas volume on the blades with a different NPSH is shown in Figure 8. Serious cavitation occurs in the experimental plastic centrifugal pump, which is consistent with the actual situation.
3.2. Research on Structural Characteristics of Impeller Based on One-Way Fluid-Structure Interaction. Two-way fluidstructure interaction is to solve unknowns in the solid domain and the fluid domain simultaneously, which requires higher requirements on computers. Considering the small flow rate and slow speed of the designed impeller, this paper only considers the effect of the fluid on the impeller and adopts one-way fluid-structure interaction to study the structural characteristics of the plastic centrifugal pump impeller $[12,13]$. In this paper, a different pressure is applied to the fluid, and the corresponding pressure load is applied to the impeller to study the deformation of the impeller under different pressures. In mechanical, the equivalent stress and deformation of the impeller are obtained, as shown in Figures 9 and 10, respectively.

It can be seen from Figure 10 that

(1) Under the combined action of centrifugal force load and fluid pressure load, the deformation of the impeller is basically axisymmetric. From the impeller inlet to the impeller outlet, the deformation of the impeller increases gradually, and the maximum deformation occurs at the outer edge of the impeller.

(2) When $1 \mathrm{~atm}$ pressure is applied to the fluid in the pump, the maximum equivalent stress on the impeller is about $10 \mathrm{MPa}$ and the maximum deformation on the impeller is $0.53256 \mathrm{~mm}$. The strength and deformation of the impeller meet the requirements. 

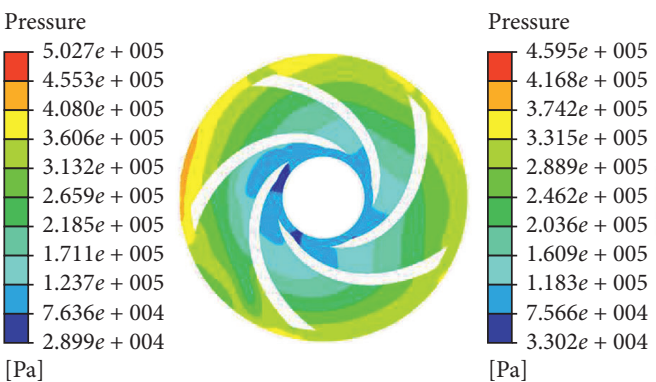

(a)

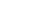

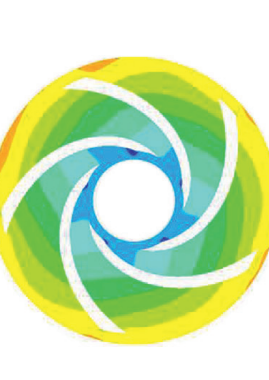

(b)

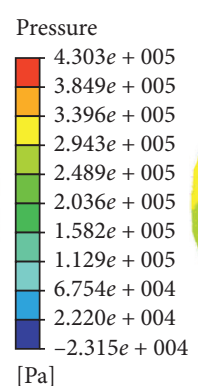

$[\mathrm{Pa}]$

Figure 6: Pressure cloud chart under different working conditions. (a) 0.6Q, (b) Q, and (c) 1.4Q.

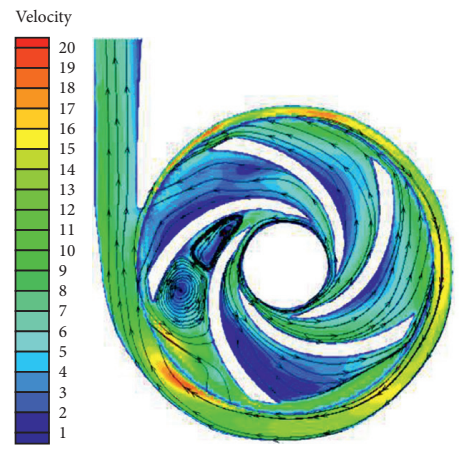

(a)

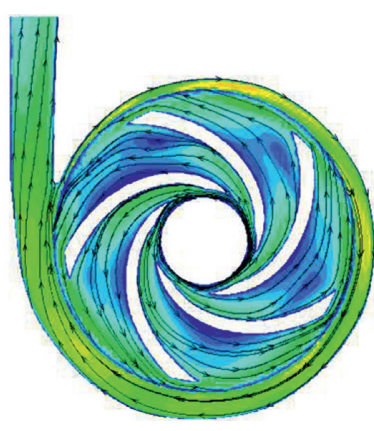

(b)

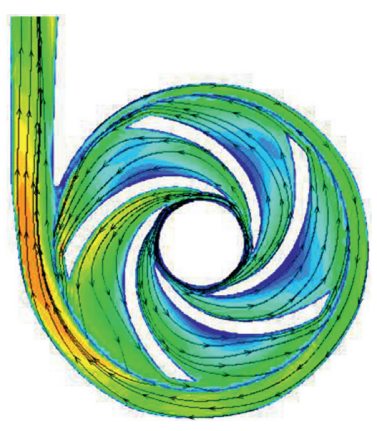

(c)

FIGURE 7: Velocity cloud chart and streamline chart under different working conditions. (a) 0.6Q, (b) Q, and (c) 1.4Q.

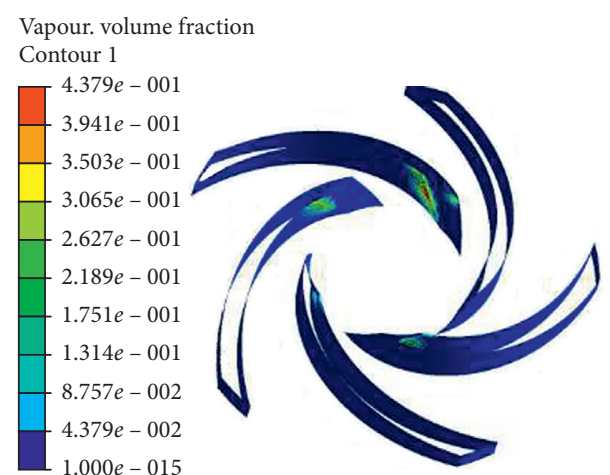

(a)

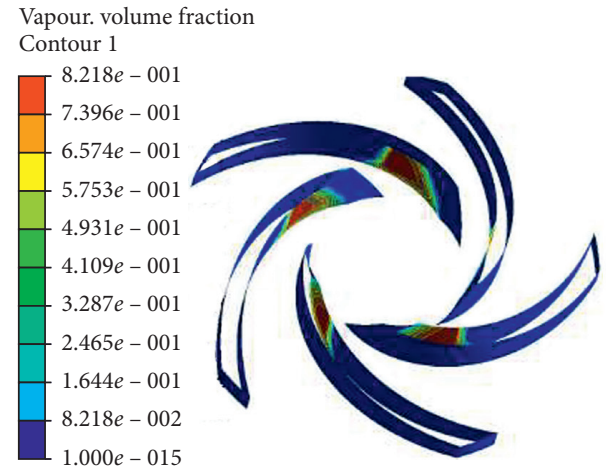

(c)

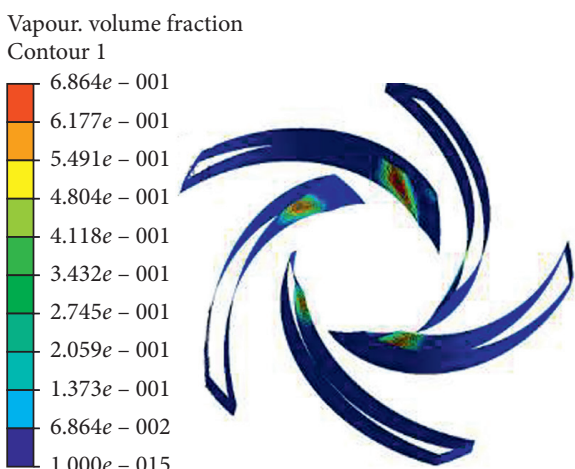

(b)

Vapour. volume fraction Contour 1

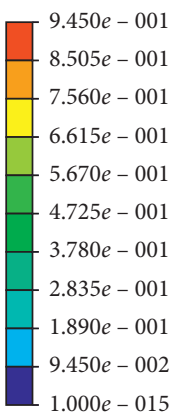

$1.000 e-015$

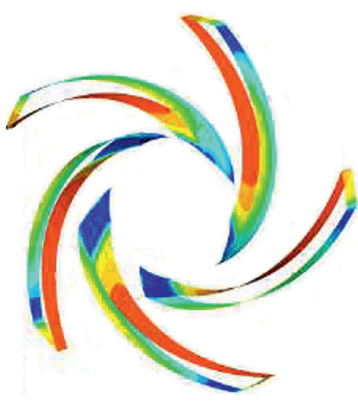

(d)

Figure 8: Cavitation on the blades with different NPSHs. (a) NPSH $=5 \mathrm{~m}$. (b) NPSH= $3.5 \mathrm{~m}$. (c) NPSH $=2 \mathrm{~m}$. (d) NPSH $=1 \mathrm{~m}$. 


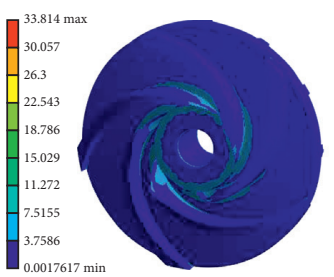

(a)

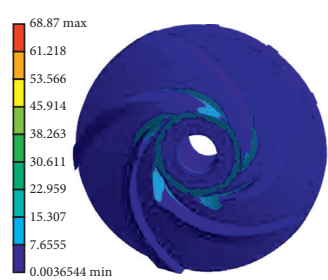

(b)

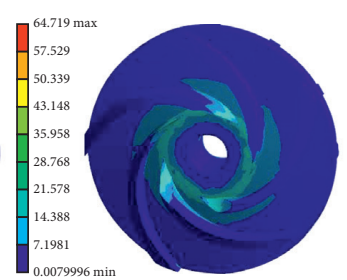

(c)

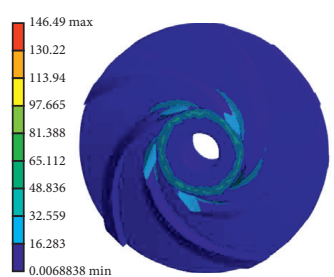

(d)

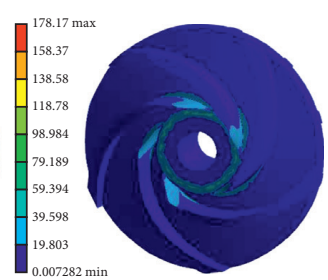

(e)

Figure 9: Equivalent stress diagram of the impeller surface. (a) $1 \mathrm{~atm}$. (b) $3 \mathrm{~atm}$. (c) $5 \mathrm{~atm}$. (d) 8 atm. (e) $10 \mathrm{~atm}$.

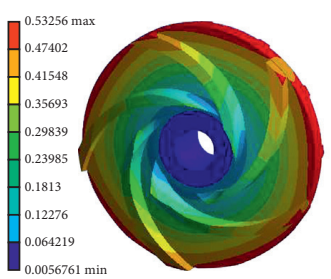

(a)

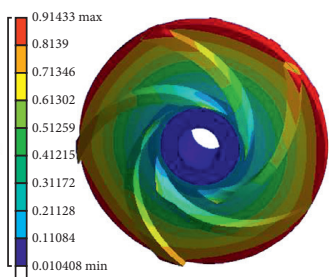

(b)

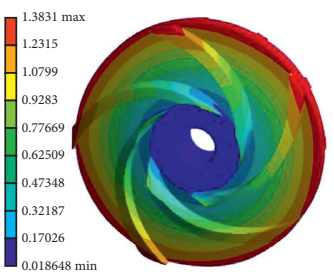

(c)

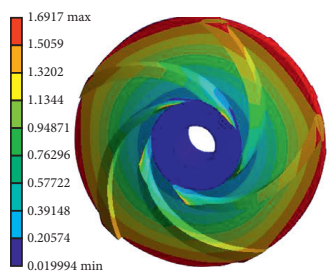

(d)

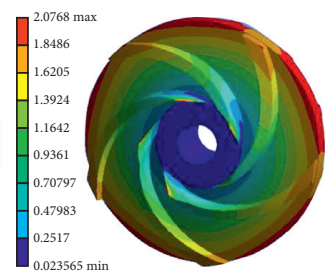

(e)

Figure 10: Deformation diagram of the impeller surface. (a) 1 atm. (b) 3 atm. (c) 5 atm. (d) 8 atm. (e) 10 atm.

(3) When the force applied to the fluid is increasing, the total deformation of the impeller increases obviously. When $P=5 \mathrm{~atm}$, the maximum deformation of the blade reaches $1.3831 \mathrm{~mm}$ and the deformation at the blade inlet reaches more than $0.5 \mathrm{~mm}$. The equivalent stress has exceeded its yield strength, or even greater than its tensile strength, and there is a risk of structural damage.

(4) When $P=8 \mathrm{~atm}$, the maximum deformation of the impeller reaches $1.6917 \mathrm{~mm}$ and the equivalent stress of the blade inlet reaches above $35 \mathrm{MPa}$. The impeller structure has failed.

(5) When $P=10 \mathrm{~atm}$, the deformation of the impeller inlet reaches more than $1 \mathrm{~mm}$, and the equivalent stress is far greater than its tensile strength. The root position of the impeller breaks, resulting in the failure of the impeller structure.

\section{Research on the Influence of Blade Outlet Angle on the Performance of Plastic Centrifugal Pump}

In the hydraulic design of the plastic centrifugal pump, the blade outlet angle is often an independent variable, which is determined according to engineering experience. A large setting angle can effectively reduce the disc friction loss of the plastic centrifugal pump, but it will cause severe blade bending and flow passage diffusion, strengthen the jet-wake structure of the plastic centrifugal pump, and reduce the efficiency of the plastic centrifugal pump [14]. In order to study the influence of the outlet angle on the performance of the plastic centrifugal pump, the impeller models with outlet angles of $25^{\circ}, 30^{\circ}$, $35^{\circ}$, and $40^{\circ}$ are established in this paper, and numerical simulation is carried out at different working points.
4.1. Influence of Outlet Angle on External Characteristics of Plastic Centrifugal Pump. Figure 11 shows the corresponding external characteristic curve of the impeller model with different outlet angles. Figure 11(a) shows the $Q-\eta$ curve. With the increase of $Q$, the efficiency of the plastic centrifugal pump basically shows an upward trend. When $\beta_{2}$ reaches $40^{\circ}$, the efficiency of the plastic centrifugal pump begins to decline; Figure 11(b) shows the $Q-H$ curve. The blade outlet angle has a reasonable range to meet the performance requirements of the plastic centrifugal pump; Figure 11(c) shows the $Q-P$ curve. The value of $P$ is different under different $Q$.

4.2. Influence of Outlet Angle on Internal Flow Field in Plastic Centrifugal Pump. The internal flow field of the plastic centrifugal pump is simulated, and the pressure and velocity cloud charts of each impeller model at different working points $(0.6 Q, Q$, and $1.4 Q$ ) are obtained, as shown in Figures 12 and 13, respectively. It can be seen from Figure 12 that the pressure distribution on the impeller cross-section is more uniform than that under off-working condition. It can be seen from Figure 13 that the velocity distribution in the impeller passage is relatively uniform, and the vortex is greatly reduced. With the increase of the outlet angle, the flow pattern in the flow channel is significantly improved, but the flow channel becomes shorter, and the binding force restriction of the channel wall on the fluid is insufficient, which results in the vortex.

When $N P S H r=1 \mathrm{~m}$, gas volume fraction chart with different outlet angles is shown in Figure 14. With the increase of the outlet angle, the overall gas volume fraction increases, and the bubbles gradually fill the whole impeller flow channel, and the cavitation performance of the impeller gradually becomes poor. 


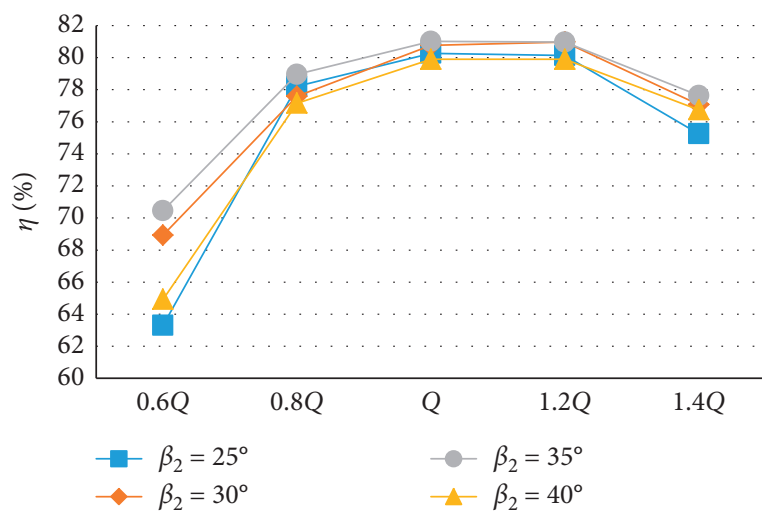

(a)

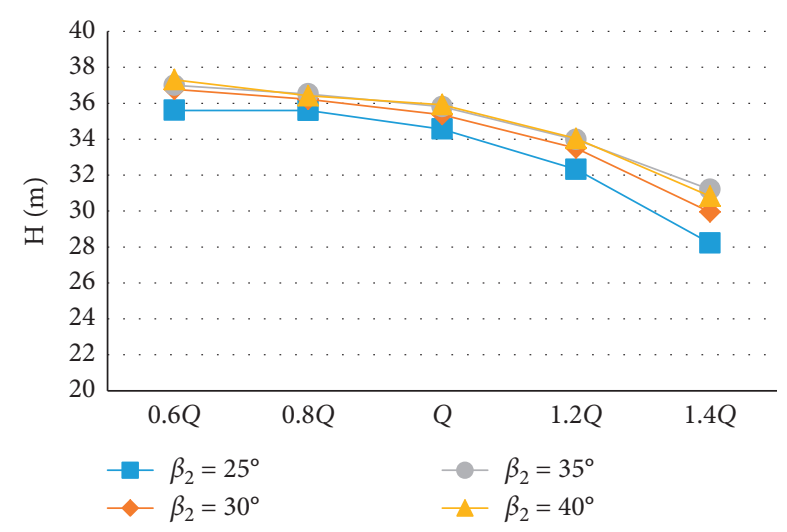

(b)

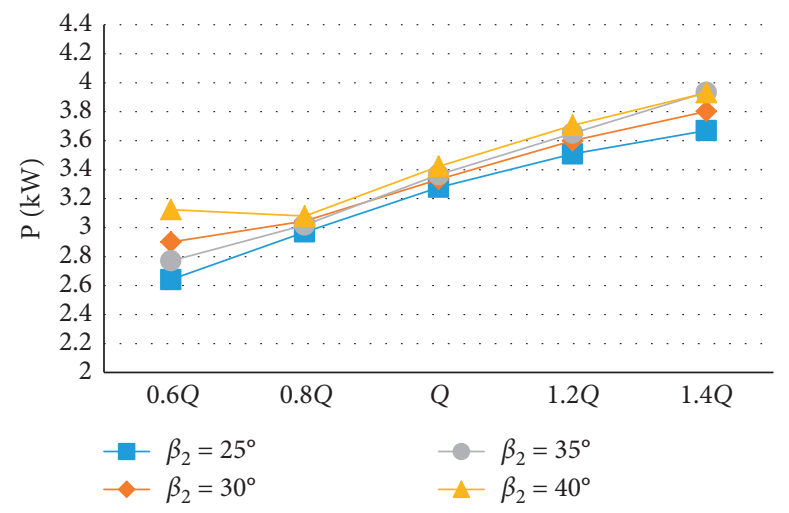

(c)

FIGURE 11: External characteristic curve of the impeller model with different outlet angles.

4.3. Research on the Influence of the Blade Outlet Angle on the Structural Characteristics of the Plastic Centrifugal Pump Based on Fluid-Structure Interaction. Figure 15 shows the equivalent stress diagram of each impeller under different fluid loads. It can be seen from the figure that the maximum equivalent stress exists at the impeller inlet and the whole blade root. When the plastic centrifugal pump transports the fluid under normal pressure, the impeller strength can meet the requirements; with the increase of working pressure, when $P=5 \mathrm{~atm}$, the impeller inlet and root have different degrees of structural damage.

According to the one-way fluid-structure interaction, the deformation of each impeller under different fluid loads is obtained, as shown in Figure 16. It can be seen from Figure 16 that when the plastic centrifugal pump works under the same pressure, the blade deformation basically increases with the increase of the outlet angle. When the working pressure increases, the difference of blade deformation under different angles is bigger. When the plastic centrifugal pump works under the condition of atmospheric pressure and negative pressure, the difference of impeller deformation is not obvious with the increase of the outlet angle, but when the plastic centrifugal pump works under the condition of high pressure (the impeller does not have structural damage), the difference of blade deformation is obvious with the increase of outlet angle. The effect of large deformation of the blade on flow field should be considered. When the larger outlet angle is determined in the hydraulic design, the blade should be thickened properly.

\section{Research on the Influence of Blade Inlet Angle on the Performance of Plastic Centrifugal Pump}

In order to study the influence of the blade inlet angle on the performance of the plastic centrifugal pump, a design method of the blade inlet angle is proposed in this section. The paper first determines the value of the wrap angle and studies the influence of the wrap angle on the performance of the plastic centrifugal pump. This paper takes the outlet angle $\beta_{2}=30^{\circ}$ as an example to determine the research scheme of the inlet angle.

5.1. Research on the Influence of Blade Wrap Angle on the Performance of Plastic Centrifugal Pump. In the design of impeller structural parameters, parameters that cannot be determined directly are often selected by experience. The wrap angle is one of the key structural parameters that affect the performance of the plastic centrifugal pump. In existing studies, three-dimensional models are used for numerical simulation to determine the value of the wrap angle. However, numerical simulation is complex and not widely used in engineering. Most workers engaged in the plastic 

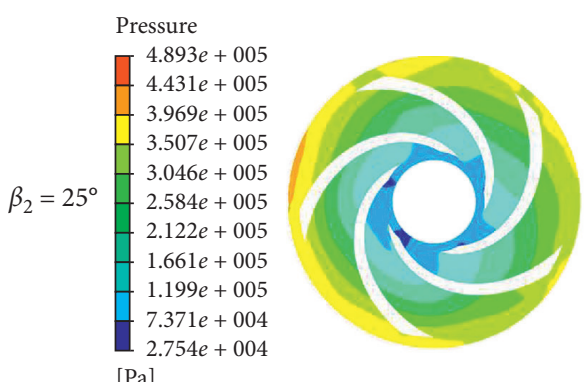

$[\mathrm{Pa}]$
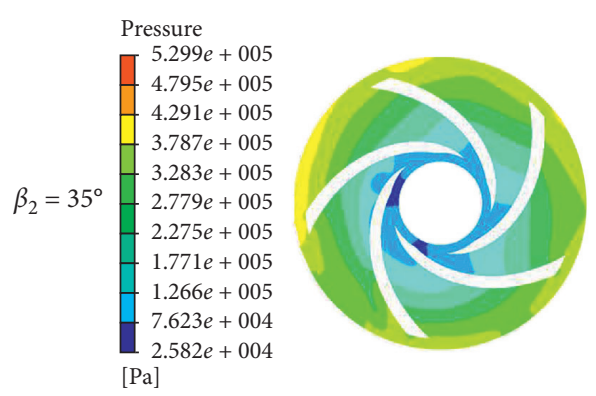

Pressure

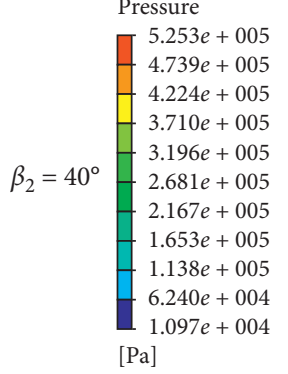

[Pa]

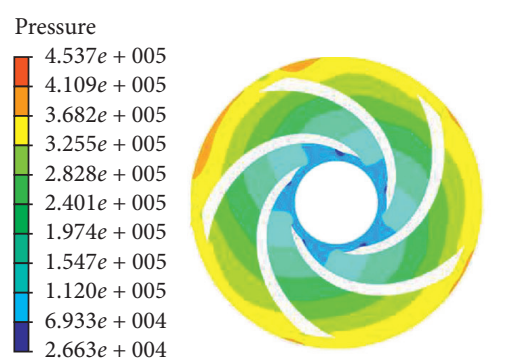

$[\mathrm{Pa}]$

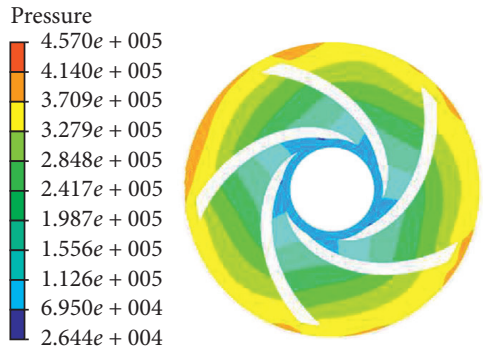

$[\mathrm{Pa}]$

Pressure

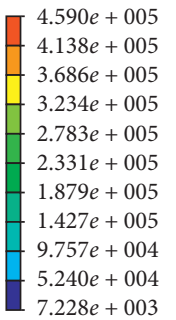

$[\mathrm{Pa}]$

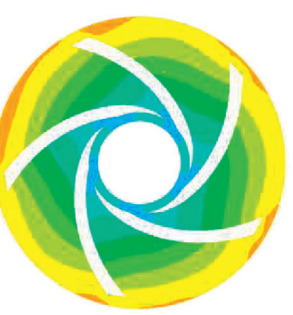

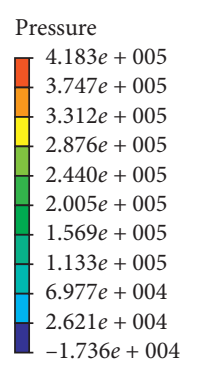

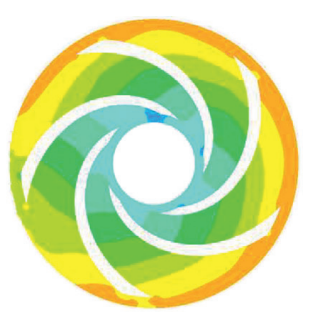

[Pa]

Pressure
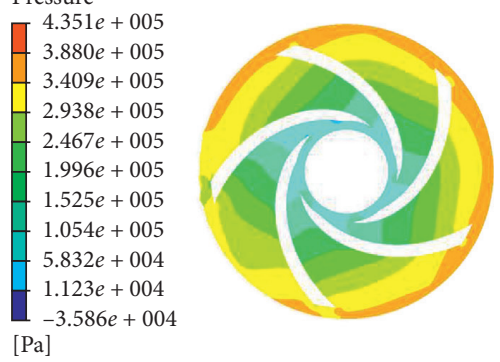

Pressure

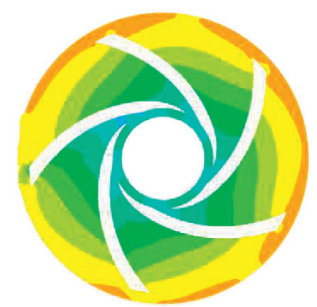

$[\mathrm{Pa}]$

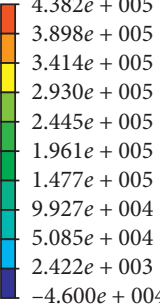

Figure 12: Pressure cloud chart with different outlet angles.

centrifugal pump still face great obstacles in numerical simulation $[15,16]$. In this paper, the wrap angle design of the plastic centrifugal pump is considered to be related to the inlet and outlet parameters of the plastic centrifugal pump, and the functional relationship between the wrap angle and the inlet and outlet parameters is established, which makes the wrap angle design reasonable. Based on the above considerations, this paper proposes a design method of the wrap angle, which establishes the functional relationship between the inlet angle, outlet angle, and wrap angle of the plastic centrifugal pump. Figure 17 is the design diagram of the wrap angle.

In the design of impeller structural parameters, some experience parameters are often needed, and these experience parameters were first proposed by $[17,18]$. According to Stepanoff velocity modulus, it can be found from Figures 7-9 in [19] that when the $n_{s}=60.871$ and $K_{M 1}=0.128$, the wrap angle is $\varphi=122.2^{\circ}$.

5.1.1. Research on the Influence of Blade Wrap Angle on the External Characteristics of Plastic Centrifugal Pump. Figure 18 shows the external characteristic curve of the plastic centrifugal pump under six different wrap angles. It can be seen from Figure 18(a) that, under the design condition, other parameters are unchanged and only the wrap angle of the blade is changed.
It can be seen from Figure 18(b) that the trend of $Q-H$ curve changes more and more steeply with the increase of the wrap angle. According to Figure 18(c), when $\varphi=110^{\circ}$, the $P$ is the largest. When $\varphi$ is larger than $110^{\circ}$, the $P$ decreases with the increase of the wrap angle.

In summary, when the $Q$ is small, the impeller flow channel diffuses, and boundary layer separation is prone to occur during fluid flow, which leads to the lower hydraulic efficiency of the plastic centrifugal pump. With the increase of the wrap angle, the blade becomes longer, the impeller flow channel diffuses better, and the possibility of flow separation in the impeller decreases gradually. However, when the wrap angle continues to increase, the friction loss in the plastic centrifugal pump increases, and the $H$ curve will decrease more and more steeply.

5.1.2. Influence of Blade Wrap Angle on Internal Flow Field of Plastic Centrifugal Pump. Figure 19 shows the pressure cloud chart of the impeller model section under different working conditions $(0.6 Q, Q$, and $1.4 Q)$. It can be seen that the pressure on the pressure surface of the blade is greater than that on the suction surface pressure when the fluid in the impeller flows under the same radius and the reverse pressure gradient; under the same wrap angle, with the increase of $Q$, the overall pressure of the impeller presents a downward trend, and the pressure distribution under the 


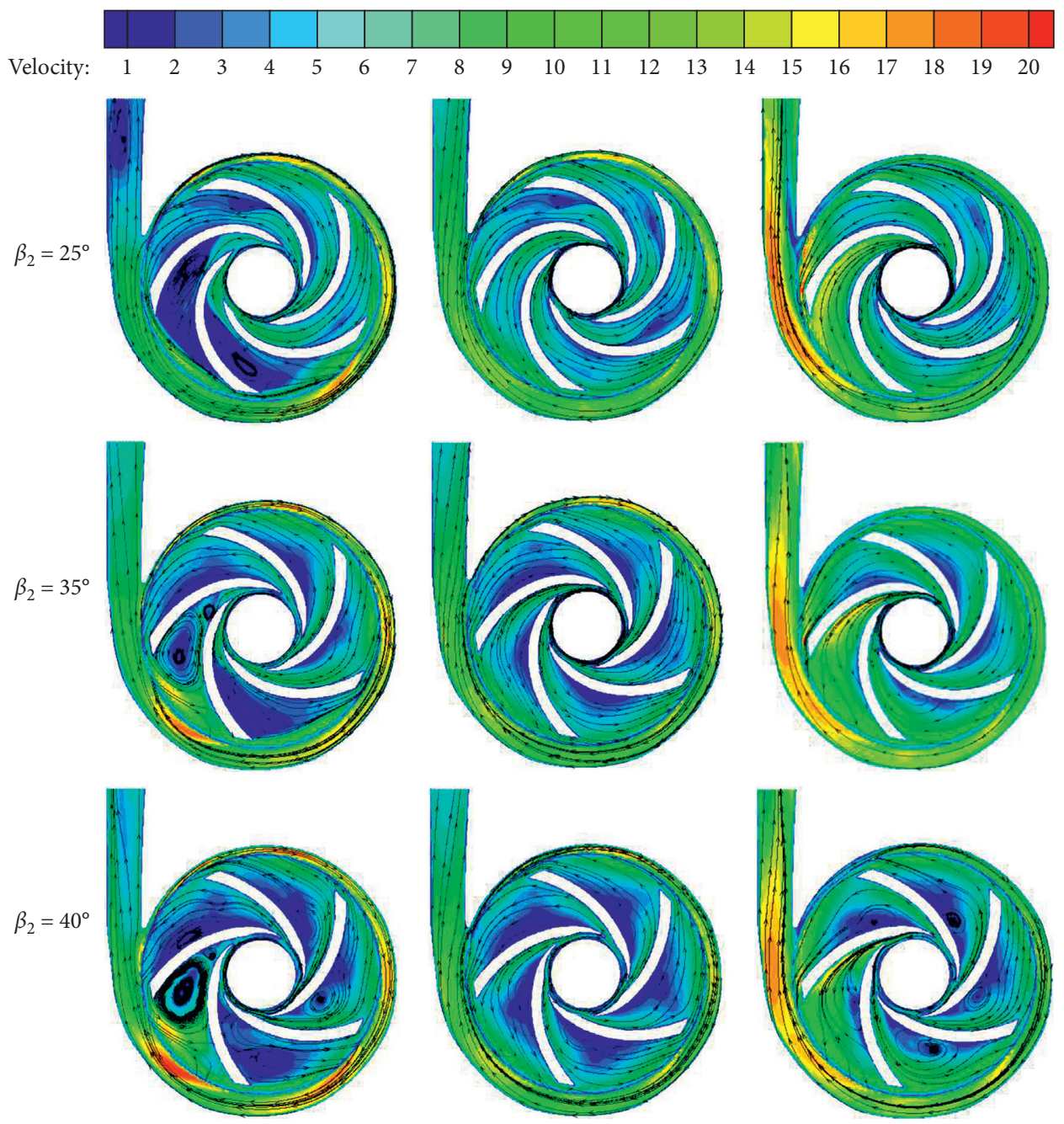

Figure 13: Velocity cloud chart with different outlet angles.

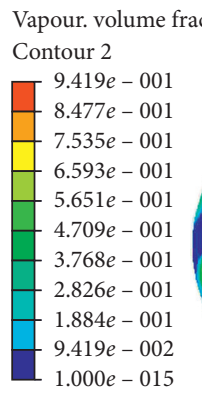

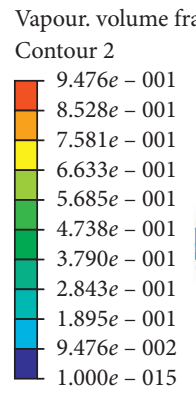

(a)

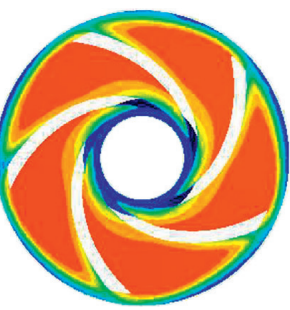

(b)

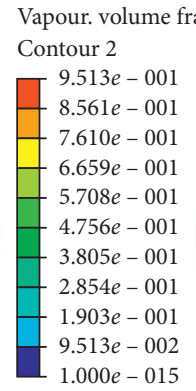

$1.000 e-015$

(c)

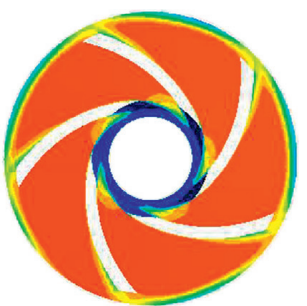

(c)

Figure 14: Gas volume fraction chart with different outlet angles. (a) $\beta_{2}=25^{\circ}$. (b) $\beta_{2}=35^{\circ}$. (c) $\beta 2=40^{\circ}$.

design working condition is more uniform than that under the off-design working condition. At the same working point, with the increase of the wrap angle, the low pressure area at the impeller inlet increases, the pressure gradient decreases gradually, and the pressure distribution is more uniform.

When the plastic centrifugal pump is running under the condition of small $Q$, the inlet pressure of the impeller increases gradually, and the range of low pressure area increases. When $\varphi=140^{\circ}$ and $\varphi=150^{\circ}$, the pressure distribution in the impeller is more uniform than that in other impeller; when it is running under the design working condition, the inlet pressure of the impeller increases gradually, when $\varphi$ increases to $140^{\circ}$, the inlet pressure of the impeller is the largest, and when $\varphi$ increases to $150^{\circ}$, the inlet pressure begins to decrease; when it is running under the 

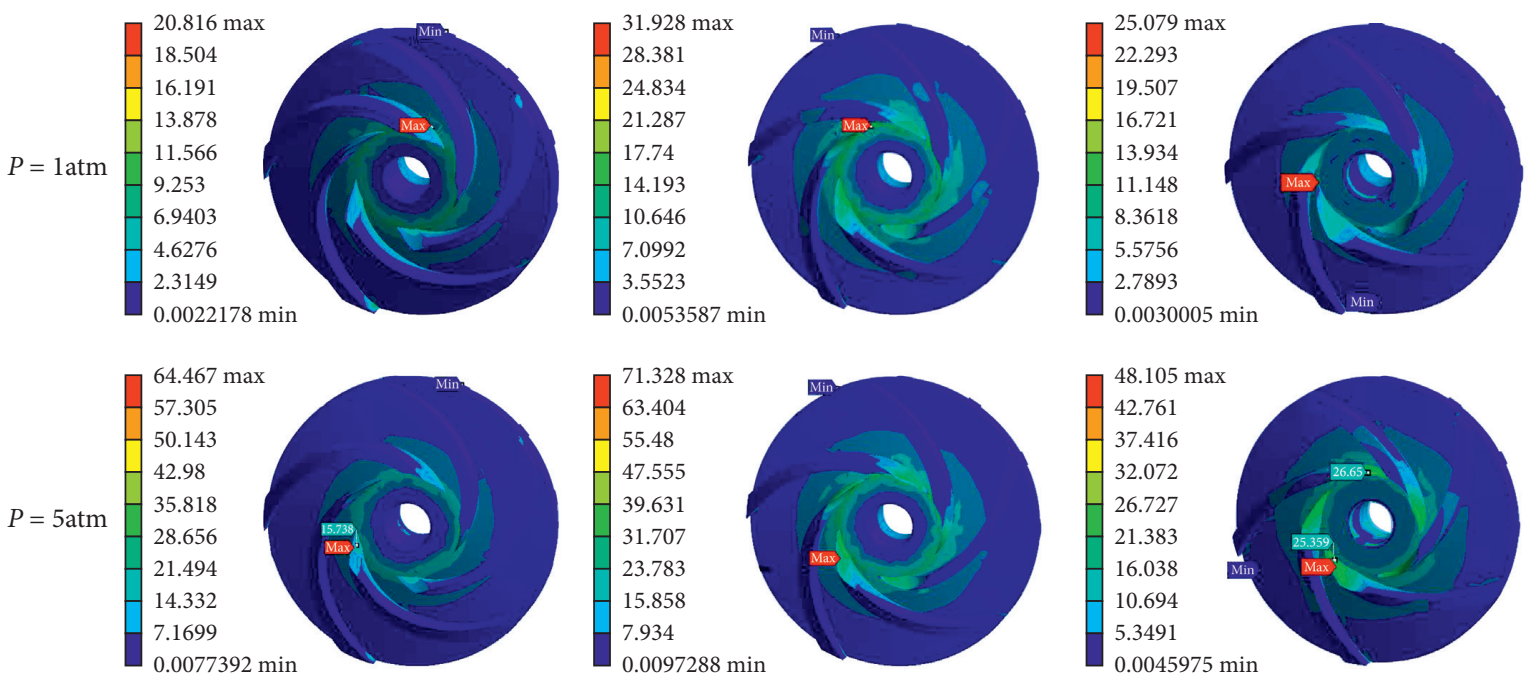

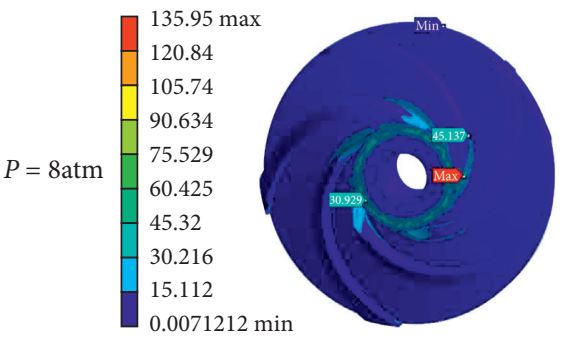

$\beta_{2}=25^{\circ}$

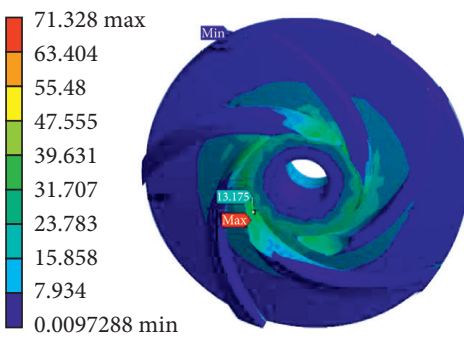

$\beta_{2}=35^{\circ}$

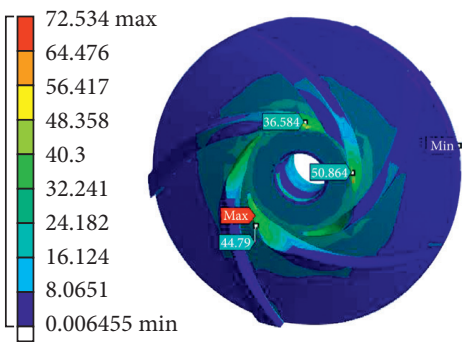

$\beta_{2}=40^{\circ}$

FIGURE 15: The equivalent stress diagram of each impeller under different fluid loads.
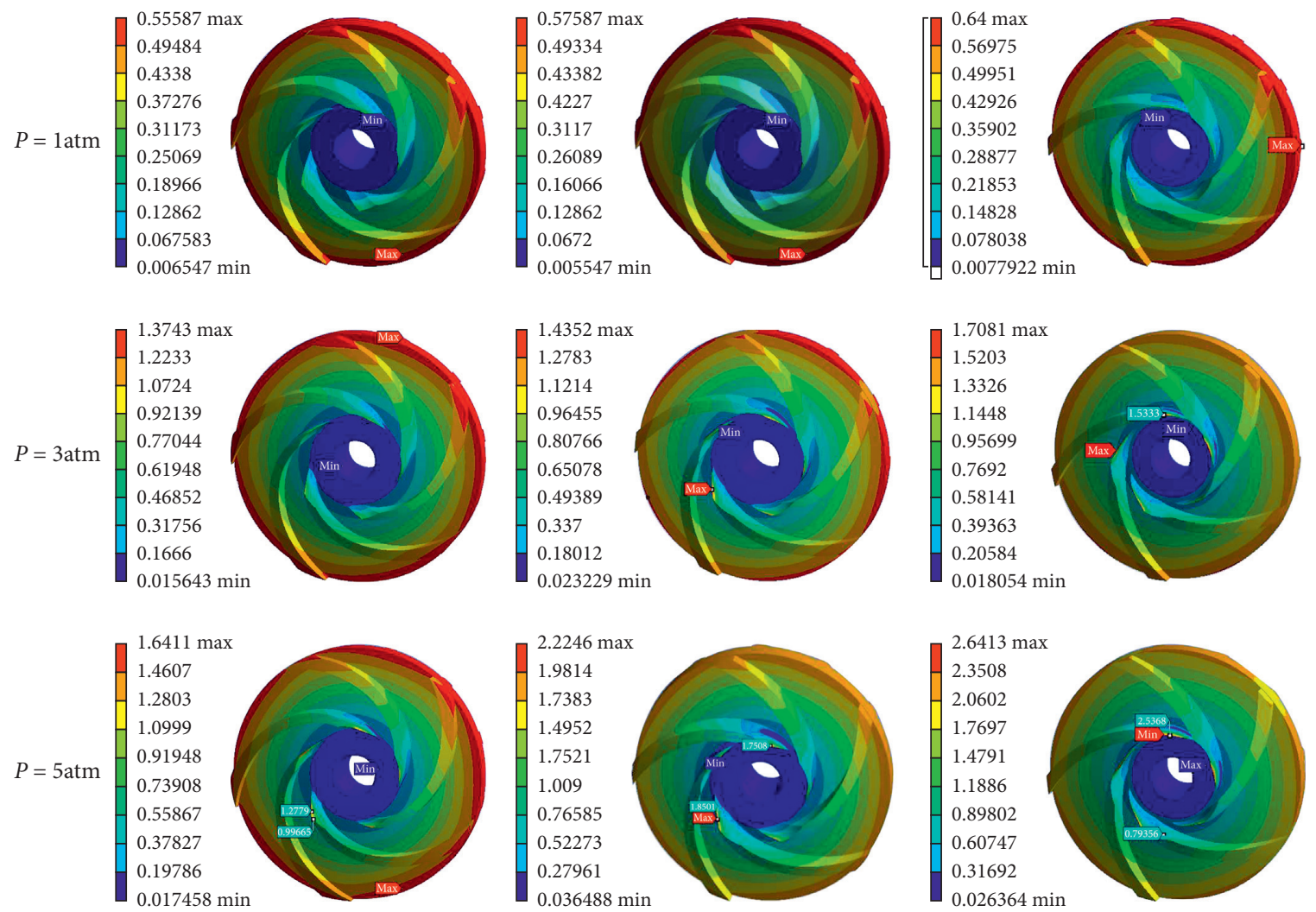

FIgURE 16: Impeller deformation under different outlet angles. 


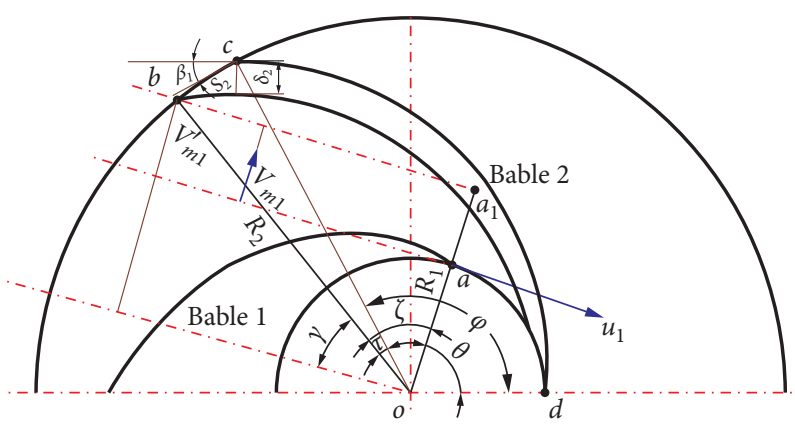

FIGURE 17: Design diagram of the wrap angle.

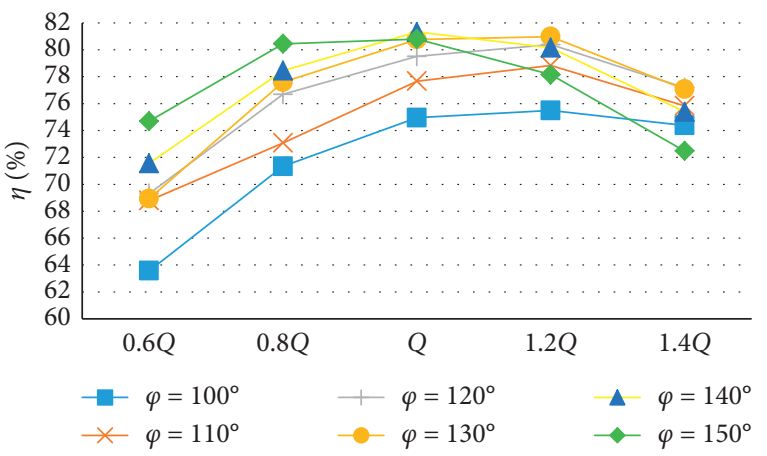

(a)

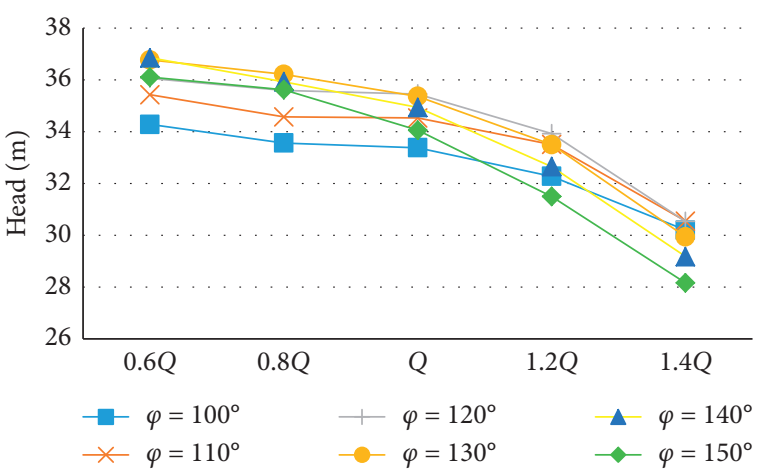

(b)

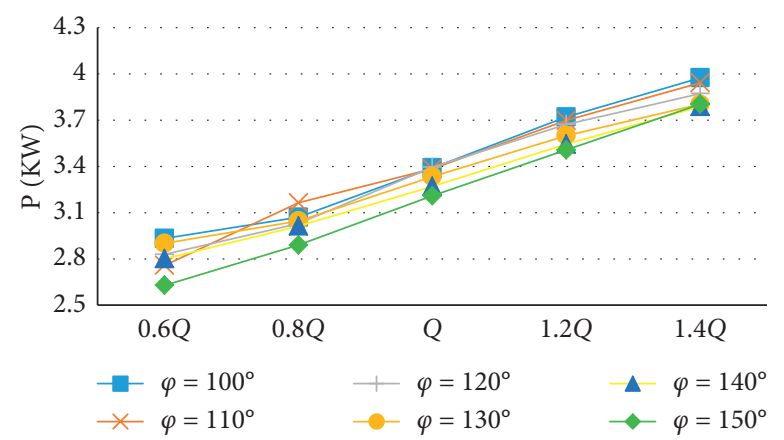

(c)

FIgURE 18: External characteristic curve of the plastic centrifugal pump under different wrap angles.

condition of large $Q$, the uneven pressure distribution on the impeller is obvious, and the change trend of impeller inlet pressure is basically consistent with the design working condition.

It can be seen from Figure 20 that the internal flow of impellers with different wrap angles meets the following laws: the internal velocity in impellers increases continuously from the inlet to the outlet, and with the increase of $Q$, the internal velocity in impellers becomes more uniform and the flow is more stable. The smaller the $Q$ is, the greater the flow gradient is and the worse the performance of the plastic centrifugal pump is. The larger the $Q$ is, the more uniform the velocity change is.

Under the condition of small $Q$, the uneven velocity in the impeller flow channel near the volute tongue is more obvious. Influenced by the impact of the volute tongue, a large number of low-speed vortex and backflow appear in the impeller flow channel. With the increase of the wrap angle, the vortex and backflow phenomenon are improved.

Under the working condition, when $\varphi=110^{\circ}$, due to the short flow channel and serious diffusion, the turbulent flow causes a lot of backflow and vortex in the impeller flow channel near the volute tongue, which leads to a lot of hydraulic loss and reduces the hydraulic efficiency of the plastic centrifugal pump. With the increase of the wrap angle, fluid flows smoothly in the plastic centrifugal pump, vortex, and backflow decrease, and the hydraulic efficiency of the plastic centrifugal pump is improved.

Under the condition of large $Q$, the flow in the impeller is obviously improved. With the increase of the wrap angle, the wake area in the blade decreases, and the flow separation phenomenon is improved. However, when the wrap angle $\varphi$ increases to $140^{\circ}$ and $150^{\circ}$, the low-speed area in the flow channel decreases, and the overall flow velocity in the flow 


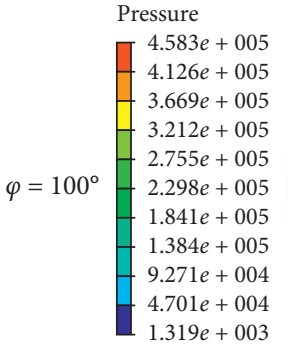

$[\mathrm{Pa}]$

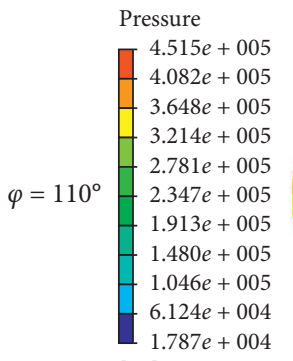

[Pa]

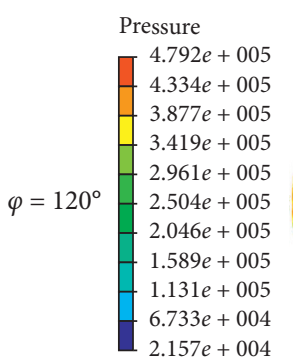

$[\mathrm{Pa}]$

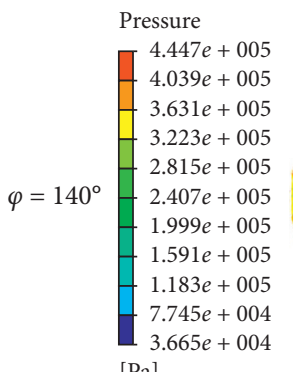

$[\mathrm{Pa}]$

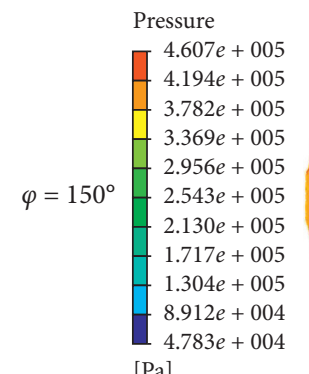

$[\mathrm{Pa}]$
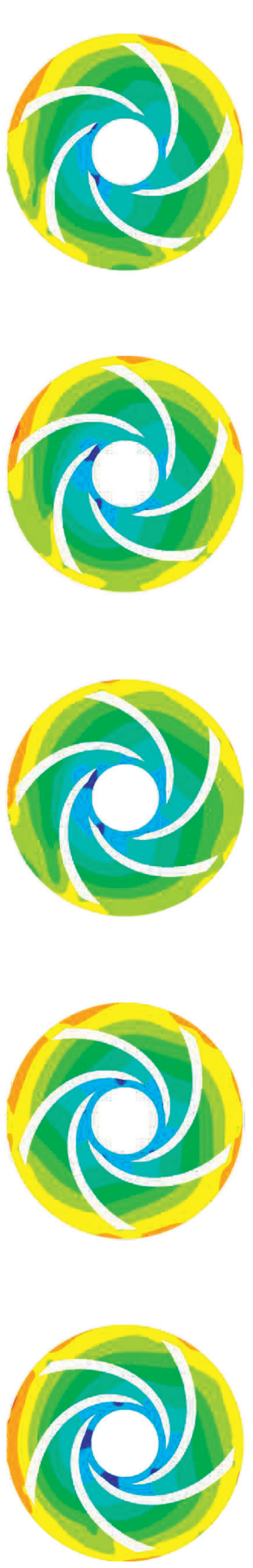

$[\mathrm{Pa}]$
Pressure

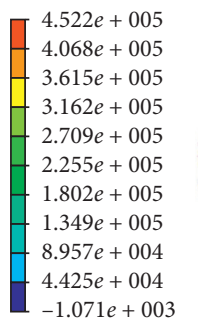

$[\mathrm{Pa}]$

Pressure

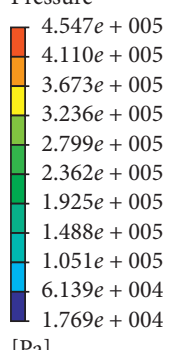

$[\mathrm{Pa}]$

Pressure

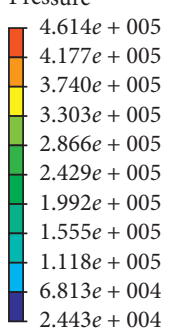

$[\mathrm{Pa}]$

\section{Pressure}

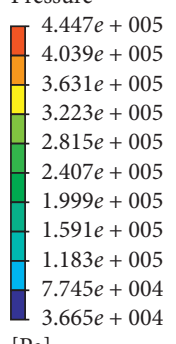

$[\mathrm{Pa}]$

\section{Pressure}

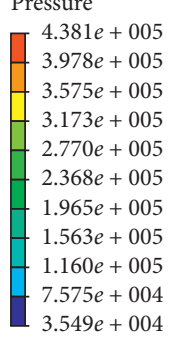

$[\mathrm{Pa}]$
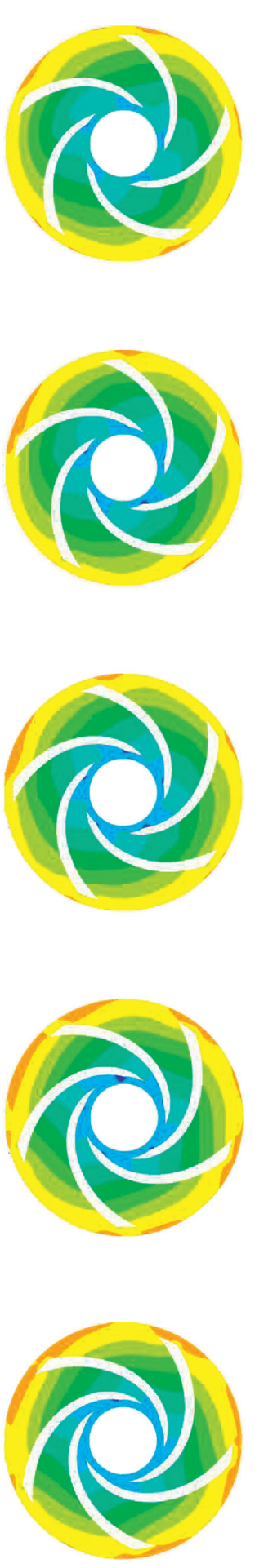

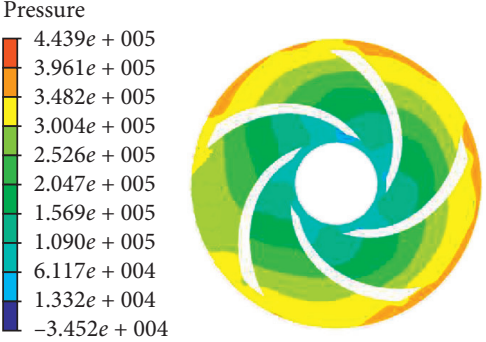

$[\mathrm{Pa}]$

Pressure
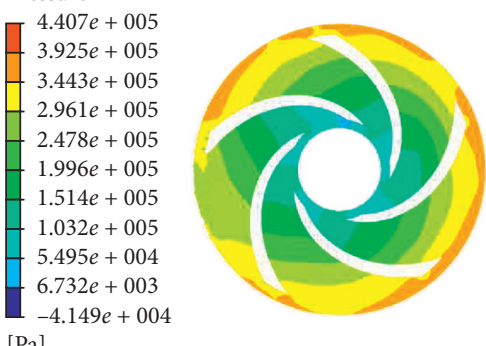

Pressure

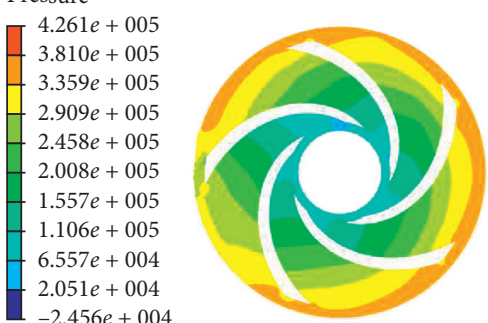

[Pa]

\section{Pressure}
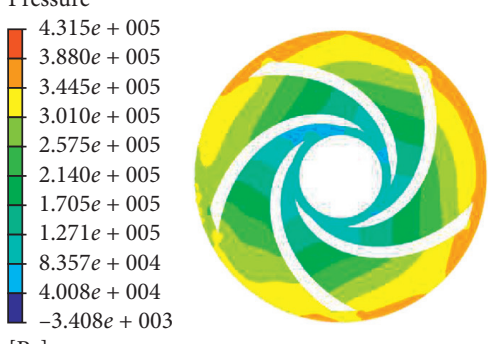

$[\mathrm{Pa}]$

\section{Pressure}
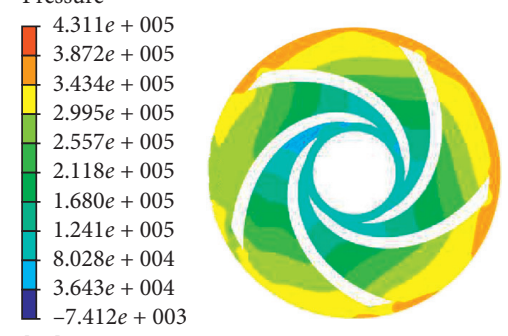

Figure 19: Pressure cloud chart of the impeller model section.

channel increases, which increases the friction resistance loss and reduces the efficiency of the plastic centrifugal pump.

5.1.3. Influence of Blade Wrap Angle on Impeller Deformation Based on Fluid-Structure Interaction. Figure 21 is the impeller deformation with different wrap angles when the plastic centrifugal pump is working under normal pressure. It can be seen that when $\varphi=100^{\circ}$, the maximum deformation on the impeller is $0.91441 \mathrm{~mm}$, the maximum deformation at the outlet of the blade suction surface profile is $1.0231 \mathrm{~mm}$, and the minimum deformation at the blade inlet is 

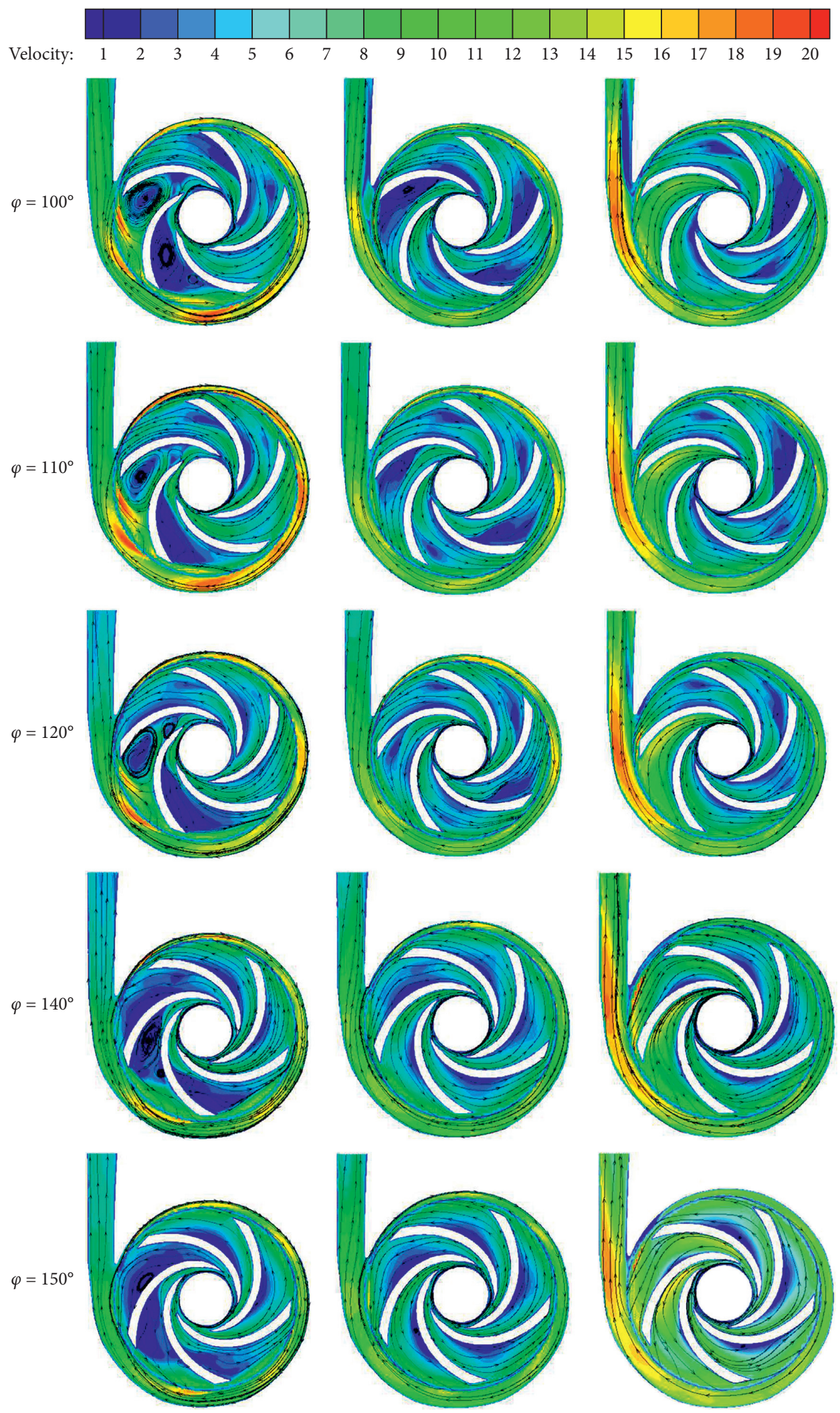

FIgURE 20: Velocity cloud chart and streamline chart of the impeller.

$0.15362 \mathrm{~mm}$. With the increase of the wrap angle, the deformation on the impeller decreases. When $\varphi=120^{\circ}$, the maximum deformation on the impeller is $0.53984 \mathrm{~mm}$, and the minimum deformation at the blade inlet is $0.065317 \mathrm{~mm}$, which is basically consistent with the maximum deformation of the impeller when $\varphi=130^{\circ}$ and $\varphi=140^{\circ}$. However, when the wrap angle of the impeller increases to $150^{\circ}$, due to the uneven pressure distribution, the deformation of the 
impeller presents obvious asymmetry, and the maximum deformation of the impeller is $0.96362 \mathrm{~mm}$ and the minimum deformation is $0.13622 \mathrm{~mm}$.

\subsection{Research on the Influence of Blade Inlet Angle on the Performance of Plastic Centrifugal Pump}

5.2.1. Design of Blade Inlet Angle. In order to study the influence of the blade inlet angle on the performance of the plastic centrifugal pump, this chapter relates the design of the blade inlet angle with other structural parameters of the blade and proposes a design method of the blade inlet angle. In the conventional design, when calculating the fluid flow angle, the inlet without prerotation is considered for design [20]. In this paper, the factors of inlet prerotation are taken into account, and the segment between points $a$ and $b$ is determined as the absolute velocity direction, and the inlet angle under the corresponding wrap angle is calculated (the following inlet angles do not include the impact angle). Figure 22 is a schematic diagram of blade geometric parameters.

According to the research in Section 4.1, the wrap angle is $\varphi=122.2^{\circ}$, and the inlet angle $\beta_{1}=7^{\circ}$ is calculated from Figure 22.

It can be seen from the above that the design of the inlet angle is related to the wrap angle and the outlet angle. When the outlet angle is constant, the inlet angle is changed, and the blade wrap angle is also changed. As shown in Figure 23, when $\beta_{1}=0$ and $\alpha_{1}=180^{\circ}$, the corresponding wrap angle is

$$
\varphi=a \cos \left(\frac{R_{2}}{R_{1}}\right)+\theta-\tau .
$$

Substitute the value $\varphi=129.8473^{\circ}$.

In the actual process, the $V_{m 1}$ is impossible to be 0 , so the wrap angle $\varphi<129.8473^{\circ}$. According to the research results in Section 4.1 , when $\varphi>130^{\circ}$, the performance of the plastic centrifugal pump with $\varphi=140^{\circ}$ does not increase compared with that of the plastic centrifugal pump with $\varphi=130^{\circ}$. When $\varphi=150^{\circ}$, the performance of the plastic centrifugal pump decreases, which is consistent with the research here.

From Figure 24, according to the relationship between velocity components, when $\varphi=\theta-\tau$ and $\varphi=60.6319^{\circ}$, the value of the inlet angle is

$$
\beta_{1}=a \tan \left(\frac{v_{m 1}}{u_{1}}\right) .
$$

By substituting the data, we can get $\beta_{1}=15.3426^{\circ}$.

According to the above research, six groups of impeller models can be preliminarily established, as shown in Table 3.

For the impeller models in Table 3, it is found in the process of drawing the impeller model that when the thickness of the inlet and outlet remains unchanged and the thickness is uniformly thickened from the inlet to the outlet, if $\varphi \leq \theta-\tau\left(\varphi \leq 60.6319^{\circ}\right)$, there is no intersection between the suction surface profile of the blade and the outer diameter of the impeller, and the blade profile does not converge, so the value range of the blade inlet angle is $0<\theta<15.3426^{\circ}$ and the range of the wrap angle corresponding to the blade inlet angle is $60.6319^{\circ}<\varphi<129.8473^{\circ}$ It can be seen from the actual drawing that when the inlet angle reaches $14.5^{\circ}$, the blade profile is not convergent, so the range of the above angle needs further study.

\subsubsection{Influence of Blade Inlet Angle on Internal Flow Field in} Plastic Centrifugal Pump. In order to study the influence of the inlet angle on the performance of the pump, this paper establishes several groups of models for numerical simulation according to different angles and uses ANSYS CFX to simulate the flow field. Table 4 is the external characteristic parameter obtained by the simulation of the design model under the working condition. It can be seen from Table 4 that when the outlet angle is constant, the absolute speed direction of the inlet is changed, and the inlet angle increases gradually, and the efficiency and head of the plastic centrifugal pump decrease.

Take $\beta_{2}=30^{\circ}$ as an example, analyze the internal velocity cloud chart of the impeller with different inlet angles, as shown in Figure 25. It can be seen that, with the increase of the inlet angle, the low velocity area on the pressure surface of the blade becomes more obvious, the possibility of boundary layer separation increases, the low velocity area on the suction surface of the blade becomes larger, resulting in a large number of vortices and flow separation, and the structure of jet wake in the impeller increases. The main reason is that the increase of the inlet angle causes weakness of the blade on fluid control.

\subsubsection{Research on the Influence of Blade Inlet Angle on the} Structural Characteristics of the Impeller of Plastic Centrifugal Pump. Figure 26 shows the deformation of impeller models with different inlet angles under constant pressure load of $\beta_{2}=30^{\circ}$. It can be seen from the figure that, under normal pressure load, with the increase of the inlet angle, the blade deformation decreases and then increases. When $\beta_{1}=7^{\circ}$, the load on the impeller is obviously uneven, the maximum deformation reaches $0.97388 \mathrm{~mm}$, and the maximum deformation of the blade inlet is about $0.3 \mathrm{~mm}$; when $\beta_{1}=13^{\circ}$, the maximum deformation of the blade is about $0.57258 \mathrm{~mm}$, the overall deformation is significantly reduced, but the deformation of the blade inlet increases about $0.3 \mathrm{~mm}$; with the further increase of the blade inlet angle, the overall deformation of the impeller continues to increase, when $\beta_{1}=14^{\circ}$, the impeller inlet bears the maximum load, and the deformation reaches $0.81869 \mathrm{~mm}$.

\section{Optimization of Blade Angle Based on Hydraulic Loss}

6.1. Optimization of Blade Angle Based on Hydraulic Loss. In order to find the optimal outlet angle and the added impact angle, this paper takes the minimum hydraulic loss and cavitation loss in the impeller as the objective to establish an optimization model for optimization. In [21], the hydraulic loss in the impeller is divided into five kinds, and the loss coefficient under different $N_{s}$ is obtained according to linear regression, which improves the accuracy of hydraulic loss calculation. Because the blade angle has obvious influence on the cavitation of the plastic centrifugal pump, 


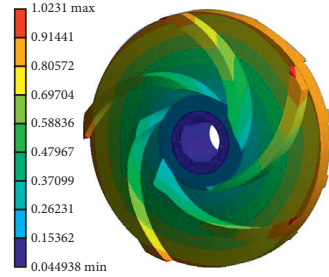

(a)

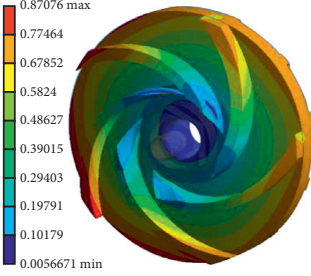

(b)

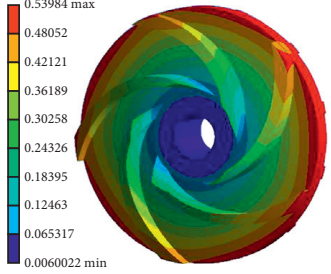

(c)

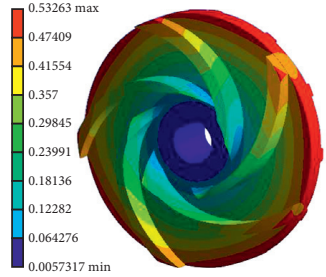

(d)

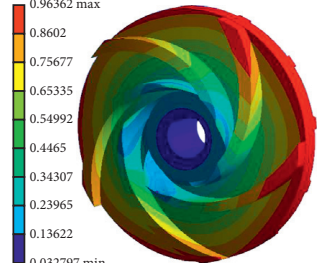

(e)

FIgURE 21: Impeller deformation with different wrap angles.

(a) $\varphi=100^{\circ}$.

(b) $\varphi=110^{\circ}$.

(c) $\varphi=120^{\circ}$.

(d) $\varphi=140^{\circ}$.

(e) $\varphi=150^{\circ}$.

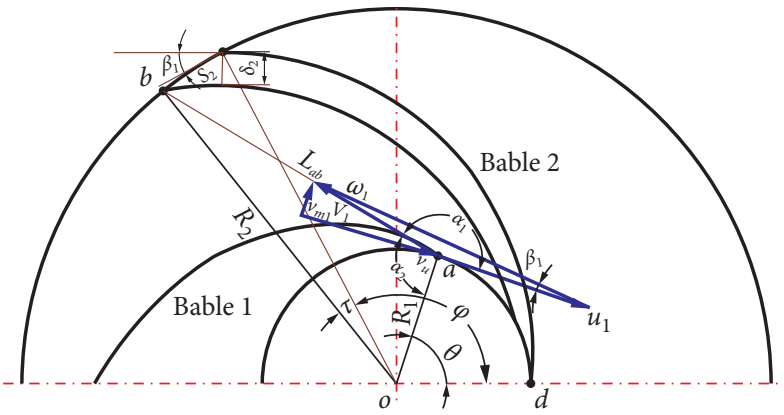

Figure 22: Schematic diagram of blade geometric parameters.

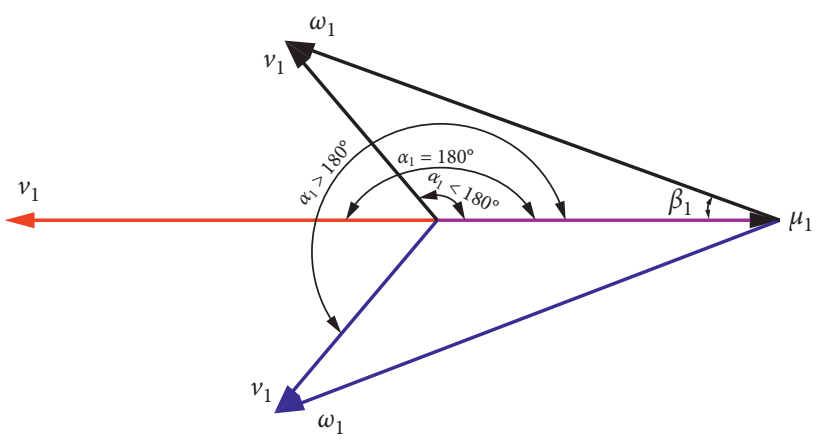

FIGURE 23: Schematic diagram for determination of the range of the inlet angle.

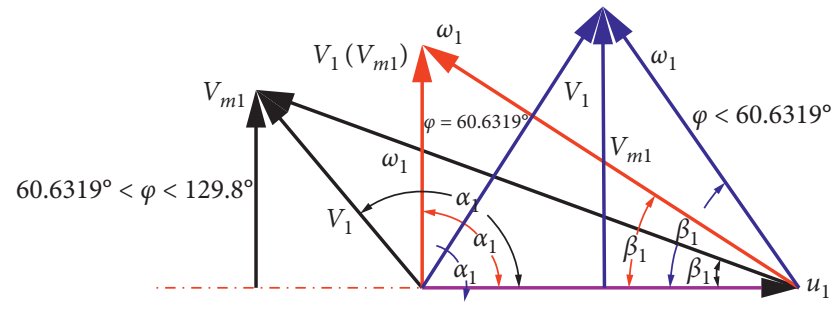

FIGURE 24: Inlet speed triangle under different inlet setting angles.

only optimizing the efficiency cannot guarantee its cavitation performance. If we want to reduce the NPSH of the plastic centrifugal pump, we usually change the inlet diameter of the plastic centrifugal pump and the blade angle, so we still need to introduce the minimum objective function
TABle 3: Parameters of impeller models.

\begin{tabular}{lcc}
\hline Model & Inlet angle $\beta_{1}\left(^{\circ}\right)$ & Wrap angle $\varphi\left({ }^{\circ}\right)$ \\
\hline Model 1 & 7 & 122.3022 \\
Model 2 & 9 & 117.5788 \\
Model 3 & 11 & 109.4721 \\
Model 4 & 13 & 93.8815 \\
Model 5 & 14 & 81.2838 \\
Model 6 & 15.3426 & 60.6319 \\
Model 7 & 16 & 51.1620 \\
\hline
\end{tabular}

of cavitation. In this paper, we use the method of the weight coefficient to deal with the multiobjective function. For the weight of each objective, the efficiency is twice as much as cavitation, and the inlet angle and outlet angle are selected as optimization variables. The range of the outlet angle is

$$
15^{\circ} \leq \beta_{2} \leq 40^{\circ} \text {. }
$$

According to the calculation, the range of the inlet angle is

$$
6^{\circ} \leq \beta_{1} \leq 35^{\circ} \text {. }
$$

Use MATLAB to program and get the optimized data, as shown in Table 5.

Based on the hydraulic loss, taking the highest hydraulic efficiency and the minimum NPSH as the objective function, the optimal angles are $\beta_{1}=19^{\circ}$ and $\beta_{2}=33^{\circ}$.

\section{Experimental Verification}

In order to verify the effect of the blade angle on the performance of the plastic centrifugal pump, several points were selected and $3 \mathrm{D}$ models were printed.

7.1. Impeller Model Printing. In order to verify the performance of the design models and summarize the influence of the blade angle on the performance of the pump from the experiment, this paper used $3 D$ printing technology to print out the impeller models of the plastic centrifugal pump and carried out the performance experiments on the models. Table 6 is the performance table of $3 D$ material (UTR9000), and Figure 27 is the impeller models printed by $3 D$ printing technology.

The printing impellers were operated on the test bench for 4 hours, there was no obvious wear and damage on the impeller appearance, and the impeller strength met the requirements. 
TABLE 4: External characteristic parameter under different model working conditions.

\begin{tabular}{|c|c|c|c|c|c|c|}
\hline Number & Outlet angle $\beta_{2} /^{\circ}$ & Inlet angle $\beta_{1} /^{\circ}$ & Wrap angle $\varphi /^{\circ}$ & Hydraulic efficiency $\eta_{\mathrm{h}} /(\%)$ & Head $\mathrm{H} / \mathrm{m}$ & Shaft power $\mathrm{P} / \mathrm{kW}$ \\
\hline 1 & \multirow{4}{*}{25} & 7 & 120.1309 & 78.2025 & 34.9143 & 3.3992 \\
\hline 2 & & 9 & 115.4908 & 77.319 & 34.2364 & 3.37129 \\
\hline 3 & & 11 & 107.3851 & 75.8128 & 33.2508 & 3.33928 \\
\hline 4 & & 13 & 91.7944 & 73.1623 & 32.3427 & 3.36576 \\
\hline 5 & \multirow{5}{*}{30} & 7 & 122.3022 & 78.6326 & 35.5208 & 3.43933 \\
\hline 6 & & 9 & 117.5788 & 77.5703 & 35.1021 & 3.44634 \\
\hline 7 & & 11 & 109.4721 & 74.6859 & 33.1619 & 3.38061 \\
\hline 8 & & 13 & 93.8815 & 73.2596 & 32.4081 & 3.36808 \\
\hline 9 & & 14 & 81.2838 & 71.9816 & 32.8627 & 3.47597 \\
\hline 10 & \multirow{6}{*}{35} & 7 & 123.7650 & 79.7254 & 35.5934 & 3.3913 \\
\hline 11 & & 9 & 119.0406 & 77.6532 & 35.6254 & 3.49296 \\
\hline 12 & & 11 & 110.9349 & 76.7474 & 35.315 & 3.50339 \\
\hline 13 & & 13 & 95.3443 & 72.6208 & 33.1782 & 3.47845 \\
\hline 14 & & 14 & 82.7465 & 71.8342 & 33.1818 & 3.51692 \\
\hline 15 & & 15 & 67.4184 & 73.1426 & 34.5774 & 3.59928 \\
\hline 16 & \multirow{6}{*}{40} & 7 & 124.8358 & 76.545 & 36.0313 & 3.5839 \\
\hline 17 & & 9 & 120.1115 & 75.8269 & 35.4806 & 3.56256 \\
\hline 18 & & 11 & 112.0058 & 74.915 & 35.1326 & 3.57056 \\
\hline 19 & & 13 & 96.4151 & 73.1767 & 34.1683 & 3.55503 \\
\hline 20 & & 14 & 83.8174 & 71.1099 & 32.6869 & 3.45837 \\
\hline 21 & & 15 & 68.4893 & 72.2672 & 35.2507 & 3.71381 \\
\hline
\end{tabular}

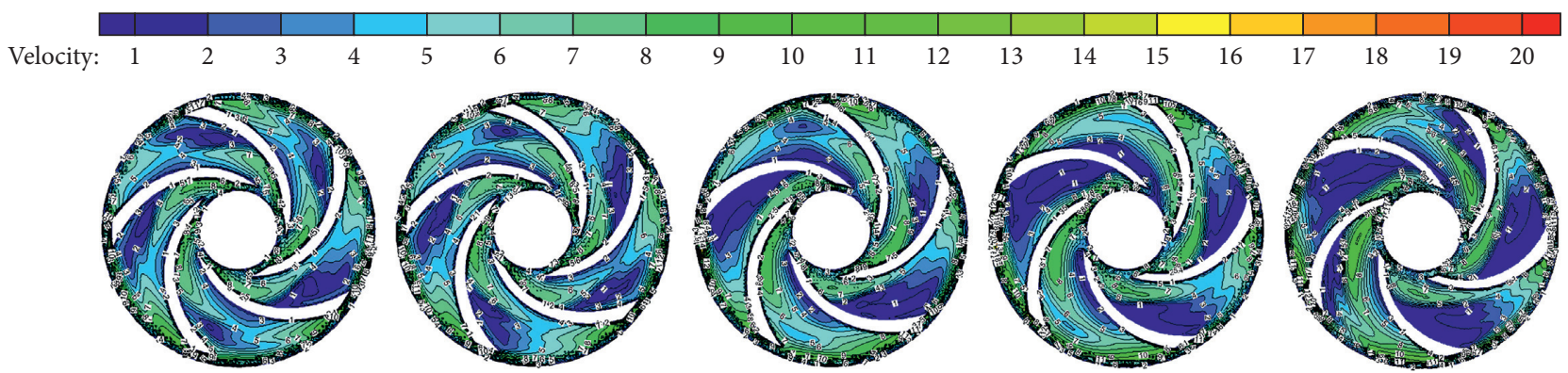

FIGURE 25: Velocity cloud chart of the impeller with different inlet angles.
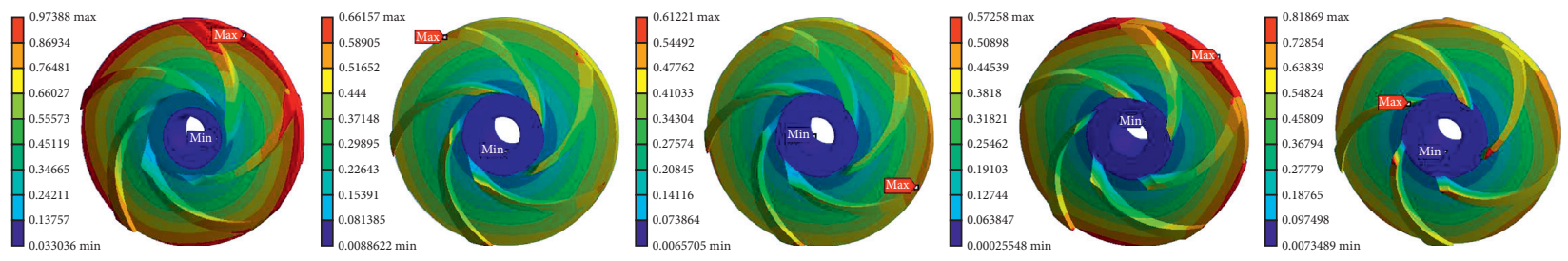

Figure 26: Cloud chart of impeller deformation under different inlet angles.

TABLe 5: Optimization results of the blade angle of the plastic centrifugal pump.

\begin{tabular}{lccc}
\hline Parameter & $\beta_{1}\left({ }^{\circ}\right)$ & $\beta_{2}\left({ }^{\circ}\right)$ & $\Phi\left({ }^{\circ}\right)$ \\
\hline After optimization & 19 & 33 & 123 \\
\hline
\end{tabular}

\subsection{Performance Experiments of Plastic Centrifugal Pump}

7.2.1. Data Analysis. According to the above impeller models, external characteristic experiments were carried out, respectively, and the fitting data are shown in Figure 28.
It can be seen that when the outlet angle $\beta_{2}$ is constant, the performance parameters of the plastic centrifugal pump basically increase first and then decrease with the increase of the inlet angle $\beta_{1}$. With the increase of the outlet angle and inlet angle, the optimal performance of the plastic 
TABLE 6: Performance parameters of 3D printing materials.

\begin{tabular}{lcc}
\hline & Performance parameter & Numerical value \\
\hline & Density $\left(\mathrm{g} / \mathrm{cm}^{3}\right)$ & 1.16 \\
Mechanical properties of cured materials & Thermal deformation temperature $\left({ }^{\circ} \mathrm{C}\right)$ & 52 \\
& Tensile strength $(\mathrm{MPa})$ & $27 \sim 31$ \\
$69-74$ & Bending strength (MPa) & \\
\hline
\end{tabular}

Note: in the figure, the first number represents the size of the inlet angle $\left(7^{\circ} \leq \beta_{1} \leq 15^{\circ}\right)$, the second number represents the size of the outlet angle $\left(25^{\circ} \leq \beta_{2} \leq 40^{\circ}\right)$, and the third number represents the size of the wrap angle.
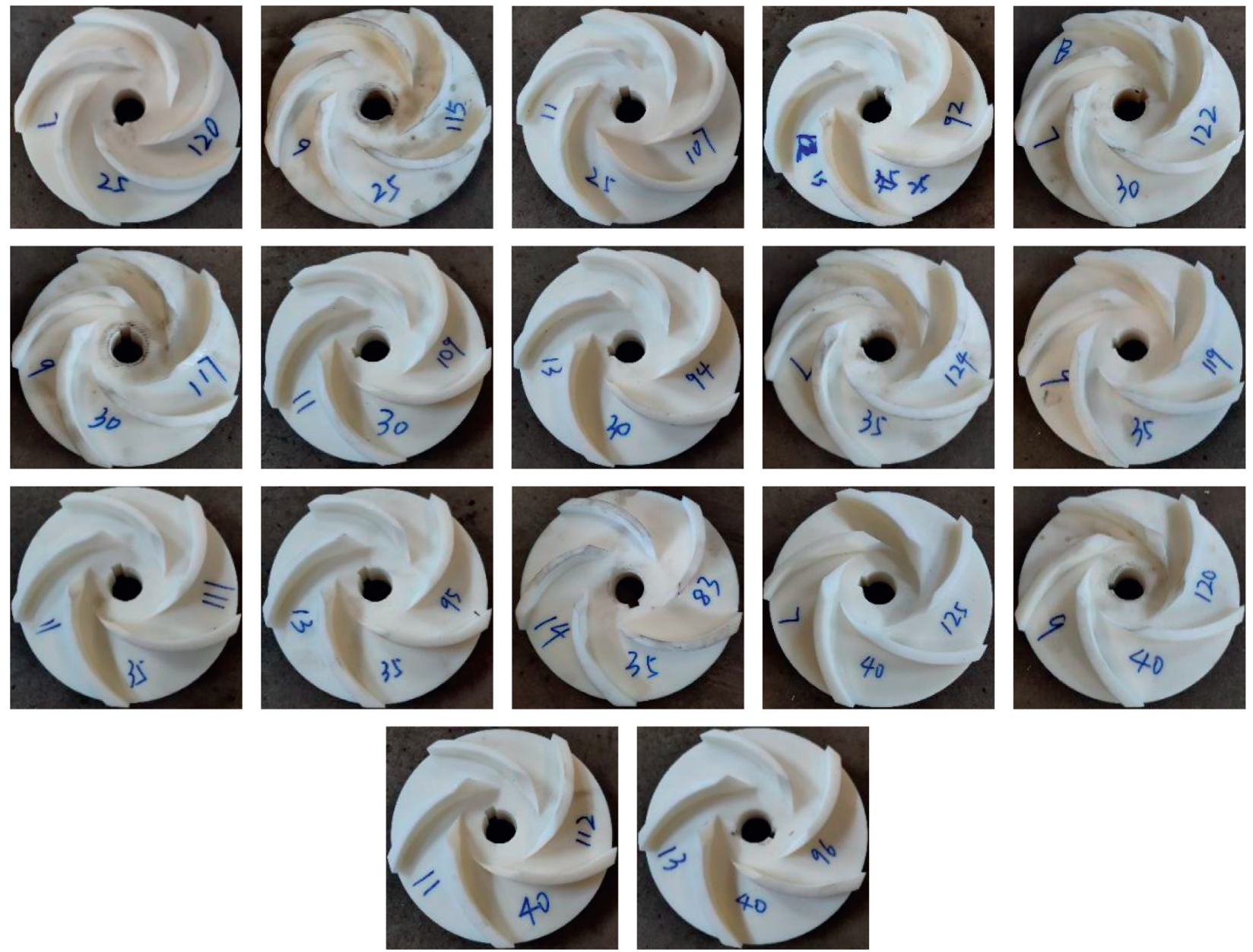

Figure 27: 3D printing impeller models of the impeller.

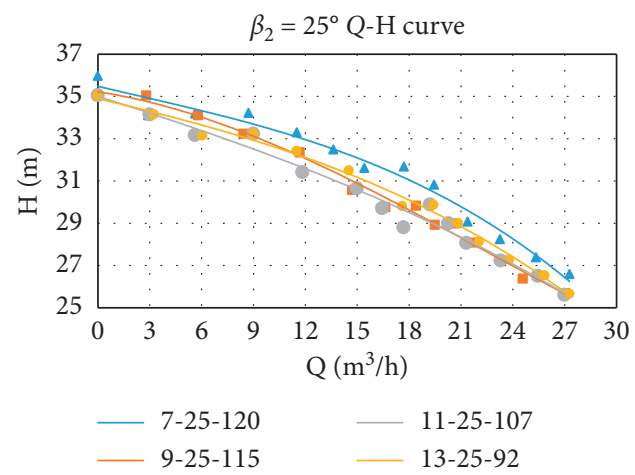

(a)

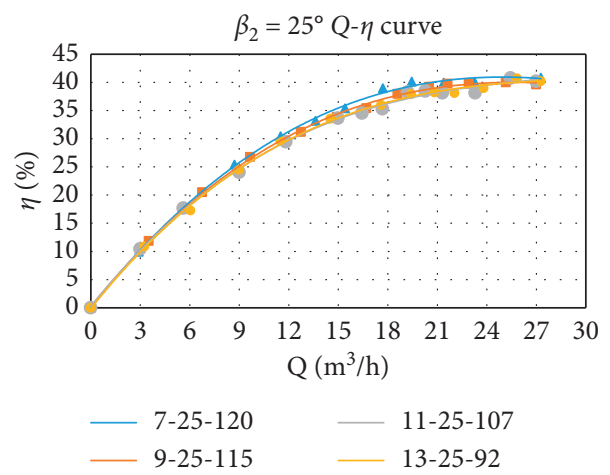

(b)

FIGURE 28: Continued. 


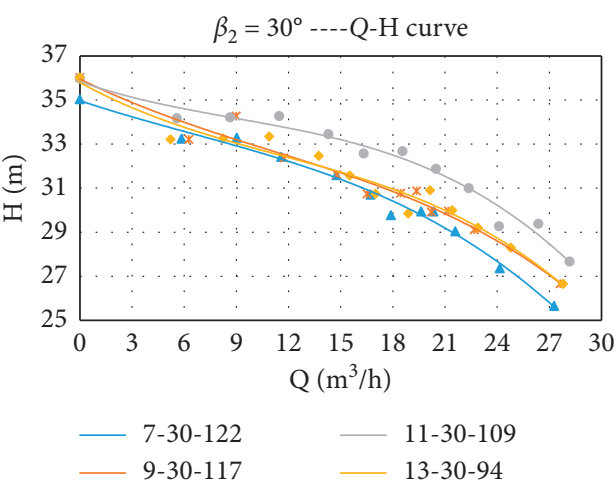

(c)

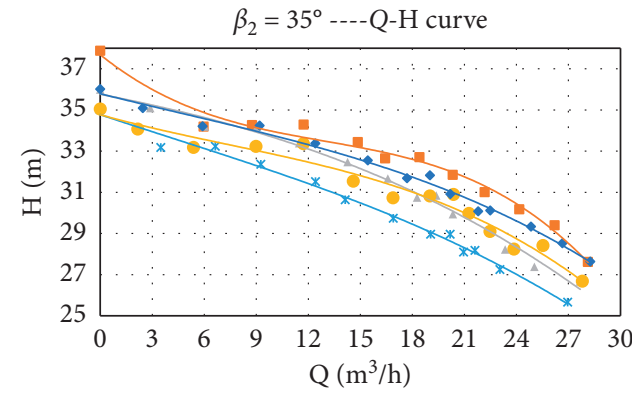

$\begin{array}{lr}7-35-124 & 13-35-95 \\ -9-35-119 & 14-35-83\end{array}$

(e)

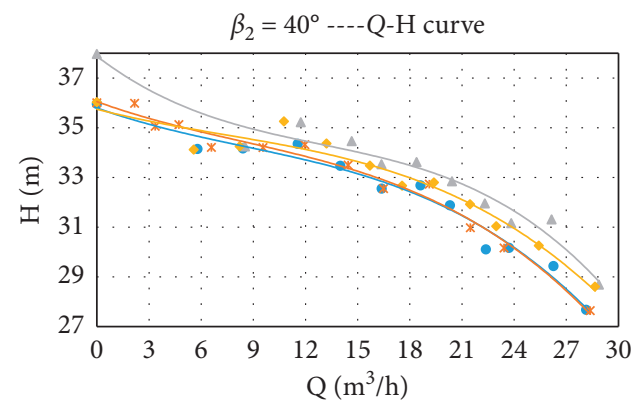

$\begin{array}{ll}-7-40-125 & 11-40-112 \\ -9-40-120 & 13-40-96\end{array}$

(g)

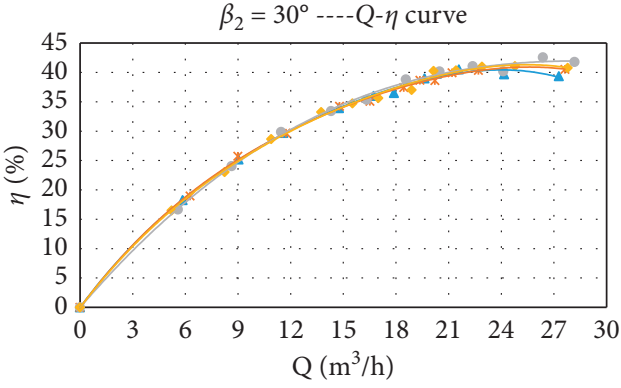

- 7-30-122

- 9-30-117

- 11-30-109

- 13-30-94

(d)

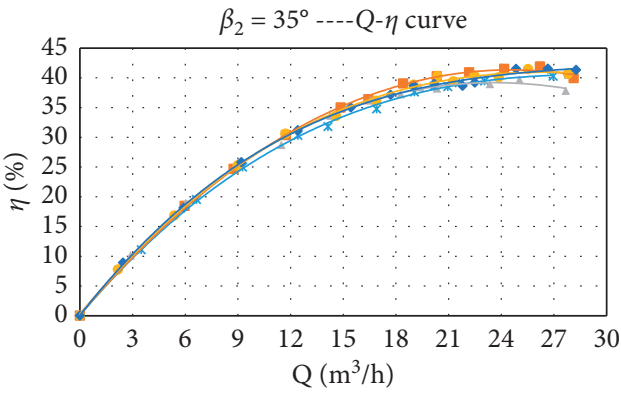

- 7-35-124 13-35-95

- 9-35-119 - 14-35-83

- 11-35-111

(f)

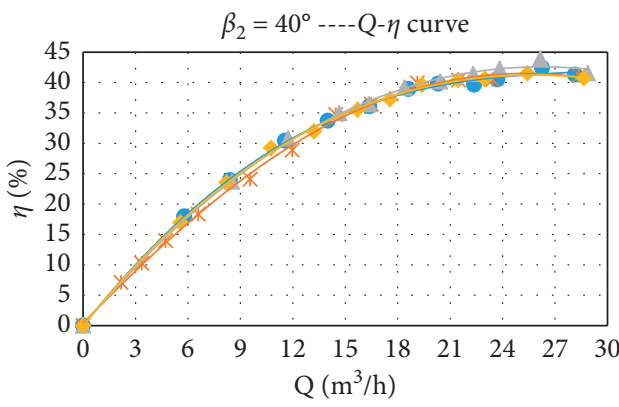

- 7-40-125 - 11-40-112

- 13-40-96

(h)

FIgURE 28: External characteristic curve of the plastic centrifugal pump.

centrifugal pump can be guaranteed. Of course, we can also adopt other methods, such as the development of an environment-friendly marine antifouling paint proposed by $\mathrm{Gu}$ et al. [22], which can be used to reduce the wear of the plastic centrifugal pump.

\section{Conclusion}

The blade angle of the plastic centrifugal pump is the key structural parameter that affects the performance of the plastic centrifugal pump. In the current research, the design of the blade angle of the plastic centrifugal pump is not effectively related to other structural parameters, and the relationship between the blade angle and performance parameters of the plastic centrifugal pump is more irregular. This paper studies the effect of the blade angle on the performance of the plastic centrifugal pump combined with experiments based on fluid-structure interaction. The main research results of this paper are as follows:

(1) The simulation results of the internal flow field were analyzed. When the plastic centrifugal pump worked under the off-design working condition, the flow field pressure distribution and velocity distribution were obviously uneven. When it worked at the small $Q$ condition, there was vortex in the impeller flow channel, the hydraulic performance of the plastic centrifugal 
pump was low, and the flow in the impeller improved with the increase of the $Q$. After the cavitation analysis of the plastic centrifugal pump, when the pressure dropped to 1 atm, the bubble filled the whole flow channel, the gas volume fraction reached 0.945, and serious cavitation occurred in the plastic centrifugal pump. Based on ANSYS Workbench, the influence of different fluid loads on the structural characteristics of the impeller under the working conditions was studied. The results showed that the deformation of the impeller was basically axisymmetric distribution, and the deformation gradually increased from the impeller inlet to the impeller outlet. When the impeller bore the pressure of about 5 atm, the impeller structure was destroyed.

(2) Under the working condition, when the outlet angle was $35^{\circ}$, the plastic centrifugal pump could reach the highest efficiency of $81.0161 \%$ and the highest $H$ of $35.8029 \mathrm{~m}$. When the outlet angle continued to increase, the efficiency and $H$ of the plastic centrifugal pump would decrease. According to the analysis of the internal flow field, it was found that, with the increase of the outlet angle, the low pressure area at the inlet of the impeller increased obviously and the pressure gradient decreased. However, when the outlet angle increased to $40^{\circ}$, the pressure distribution at the inlet of the impeller was not uniform, and the overall cavitation performance of the impeller changed. After one-way fluidstructure interaction, it was found that, under the same working pressure, the maximum deformation of the impeller caused by flow field load at different outlet angles increased with the increase of the outlet angle, and the difference increased with the increase of working pressure of the plastic centrifugal pump.

(3) With the increase of the inlet angle, the efficiency and $\mathrm{H}$ of the plastic centrifugal pump showed a decreasing trend. According to the results of internal flow field analysis, the low-speed area on the pressure surface and suction surface of the blade expands, resulting in a large number of vortices and flow separation. According to the results of fluid-structure interaction, under the normal pressure load, the deformation of the blade first decreased and then increased. When $\beta_{1}=13^{\circ}$, the deformation of the blade was the most small, $0.57258 \mathrm{~mm}$.

\section{Data Availability}

The date used to support the findings of this study are included within the article.

\section{Conflicts of Interest}

The authors declare that they have no conflicts of interest.

\section{Acknowledgments}

This article belongs to the project of the "The University Synergy Innovation Program of Anhui Province" (GXXT2019-004) and "Teaching Research Project of Anhui Education Department” (2019jyxm0229).

\section{References}

[1] X. Yang, "Analysis of the current situation and development direction of domestic plastic centrifugal pump," Chemical Equipment Technology, vol. 36, no. 6, pp. 44-46, 2015.

[2] W. Guo, Analysis of Unsteady Flow and Vibration Characteristics of Low Specific Speed Centrifugal Pump Based on TwoWay Fluid Solid Coupling, Zhejiang University of Technology, Hangzhou, China, 2017.

[3] H. Liu, H. Xu, X. Wu et al., "Effect of fluid solid coupling on internal and external characteristics of centrifugal pump," Journal of Agricultural Engineering, vol. 28, no. 13, pp. 82-87, 2012.

[4] H. Wang, D. Zhang, W. Shi, and L. Zhang, "Structural analysis and optimization of centrifugal pump volute based on fluid solid coupling," Journal of Drainage and Irrigation Machinery Engineering, vol. 32, no. 6, pp. 472-476, 2014.

[5] S. Huang, X. Zhang, X. Su, and G. Qu, "Fluid structure coupling analysis based on the whole flow field of centrifugal pump," Fluid Machinery, vol. 43, no. 11, pp. 38-42, 2015.

[6] G. Fontanals and E. Alfred, "Numerical study of the fluidstructure interaction in the diffuser passage of a centrifugal pump," Computational Methods for Coupled Problems Inence \& Engineering IV, vol. 30, no. 6, pp. 986-995, 2011.

[7] L. Zheng, "Design and experimental research of plastic chemical centrifugal pump," Rubber Technology and Equipment, vol. 42, no. 12, pp. 89-90, 2016.

[8] L. Tang, M. Liu, and F. Ma, “Thermosetting coupling analysis and parameter optimization of the plastic lining pump structure," Advances in Materials Science and Engineering, vol. 2019, pp. 1-15, 2019.

[9] Y. Wang and X. Huo, "Multiobjective optimization design and performance prediction of centrifugal pump based on orthogonal test," Advances in Materials Science and Engineering, vol. 2018, pp. 1-10, 2018.

[10] Y. Gu, S. Yu, J. Mou, D. Wu, and S. Zheng, "Research progress on the collaborative drag reduction effect of polymers and surfactants," Materials, vol. 13, no. 2, p. 444, 2020.

[11] Y. Jing, J. Zhang, M. He, and T. Wang, "Profile equation of cylindrical blade with controllable wrap angle of centrifugal pump," Irrigation and Drainage Machinery, vol. 2008, no. 5, pp. 46-49, 2008.

[12] J. Zheng, C. Yang, L. Zhu, and N. Jia, "Rotating solid coupling analysis of centrifugal pump blades," Fluid Machinery, vol. 41, no. 2, pp. 25-29, 2013.

[13] M. Bongert, J. Wüst, M. Geller et al., "Comparison of two biological aortic valve prostheses inside patient-specific aorta model by bi-directional fluid-structure interaction," Current Directions in Biomedical Engineering, vol. 4, no. 1, pp. 59-62, 2018.

[14] S. Kim, U.-B. Jeong, K.-Y. Lee, J.-H. Kim, J.-Y. Yoon, and Y.-S. Choi, "Multi-objective optimization for mixed-flow pump with blade angle of impeller exit and diffuser inlet," Journal of Mechanical Science and Technology, vol. 31, no. 11, pp. 5099-5106, 2017.

[15] Y. Bai, F. Kong, S. Yang, K. Chen, and T. Dai, "Effect of blade wrap angle in hydraulic turbine with forward-curved blades," International Journal of Hydrogen Energy, vol. 42, no. 29, pp. 18709-18717, 2017.

[16] J. Du, H. Yang, and Z. Shen, "Study on the impact of blades wrap angle on the performance of pumps as turbines used in water supply system of high-rise buildings," International Journal of Low-Carbon Technologies, vol. 13, no. 1, pp. 102108, 2018. 
[17] J. StepanoffA, Centrifugal and Axial Pumps, JohnWiley \& Sons, NewYork, NY, USA, 1957.

[18] Z. Pan, Y. Cao, W. Cao, and Y. Ni, "Selection principle of design coefficient of centrifugal impeller," Irrigation and Drainage Machinery, vol. 2008, no. 3, pp. 34-38, 2008.

[19] X. Guan, Modern Pump Theory and Design, China Aerospace Press, Beijing, China, 2011.

[20] T. Wang, F. Kong, B. Xia, Y. Bai, and C. Wang, "The method for determining blade inlet angle of special impeller using in turbine mode of centrifugal pump as turbine," Renewable Energy, vol. 109, pp. 518-528, 2017.

[21] O. Minggao, H. Liu, and S. Yuan, "Calculation of hydraulic loss of centrifugal pump," Journal of Jiangsu University (Natural Science Edition), vol. 2007, no. 5, pp. 405-408, 2007.

[22] Y. Gu, L. Yu, J. Mou et al., "Research strategies to develop environmentally friendly marine antifouling coatings," $M a-$ rine Drugs, vol. 18, no. 7, p. 371, 2020. 